\title{
Actin polymerization downstream of integrins: signaling pathways and mechanotransduction
}

\author{
Stéphane Romero ${ }^{1, *}$, Christophe Le Clainche ${ }^{2}$ and Alexis M. Gautreau ${ }^{1,3, *}$ \\ ${ }^{1}$ CNRS UMR7654, Institut Polytechnique de Paris, 91128 Palaiseau cedex, France \\ ${ }^{2}$ Institute for Integrative Biology of the Cell (I2BC), CEA, CNRS, Univ. Paris-Sud, \\ Université Paris-Saclay, 91198, Gif-sur-Yvette cedex, France \\ ${ }^{3}$ School of Biological and Medical Physics, Moscow Institute of Physics and Technology, \\ Dolgoprudny 141700, Moscow region, Russian Federation. \\ * Authors for correspondence: \\ stephane.romero@polytechnique.edu \\ alexis.gautreau@polytechnique.edu
}




\begin{abstract}
A cell constantly adapts to its environment. Cell decisions to survive, to proliferate or to migrate are dictated not only by soluble growth factors, but also through the direct interaction of the cell with the surrounding extracellular matrix. Integrins and their connections to the actin cytoskeleton are crucial for monitoring cell attachment and the physical properties of the substratum. Cell adhesion dynamics are modulated in complex ways by the polymerization of branched and linear actin arrays, which in turn reinforce ECM-cytoskeleton connection. This review describes the major actin regulators, Ena/VASP proteins, formins and Arp2/3 complexes, in the context of signaling pathways downstream of integrins. We focus on the specific signaling pathways that transduce the rigidity of the substrate and which control durotaxis, i.e. directed migration of cells towards increased ECM rigidity. By doing so, we highlight several recent findings on mechanotranduction and put them into a broad integrative perspective that is the result of decades of intense research on the actin cytoskeleton and its regulation.
\end{abstract}




\section{Introduction}

Cell adhesion is a critical process that governs many facets of cell physiology. Cell adhesion is particularly crucial to embryonic development, as well as to adult life, when tissues are repaired by wound healing or when circulating immune cells adhere to the walls of blood vessels and transmigrate across the endothelium to reach sites of infection [1-3]. It allows cells to adapt their behavior to the extracellular environment. Cell adhesion determines whether a cell remains static or starts to migrate [4-7]. It also controls proliferation and survival [8]. In cancer, cell adhesion to the extracellular matrix (ECM) allows the dissemination of tumor cells into the organism as distant metastases [9, 10]. These various examples illustrate the importance for the cell to control the dynamic remodeling of its adhesion structures.

Cell adhesions connect the ECM to the intracellular actin cytoskeleton through heterodimeric transmembrane receptors of the integrin family [11, 12]. Through the combination of diverse $\alpha$ and $\beta$ subunits, integrins recognize various ECM components, such as fibronectin, collagen or vitronectin [2]. On rigid substrates, cells develop adhesion structures called focal adhesions (FAs), which are of daunting complexity since they are dynamically remodeled during cell spreading and migration and can extend to several hundred proteins $[13,14]$. The challenge is to understand the mechanisms by which different arrays of the actin cytoskeleton produce and transmit the forces coupling adhesion structures to membrane protrusions [5]. The tensile actomyosin cytoskeleton pulls on the ECM, whereas actin polymerization pushes the membrane forward. These opposite push-pull forces are both required for the cell to sense its environment and in particular its compliance or rigidity [1517]. Biophysical properties of the environment are thus mechanotransduced into the cell through the actin cytoskeleton. Mechanotransduction determines cell decisions to migrate, survive and proliferate.

This intricate coupling of actin polymerization with cell adhesions will be detailed in this review in several sections. We will first describe the processes coupling adhesive structures to actin polymerization. We will then describe the molecular players ultimately controlling actin polymerization and the signaling pathways that integrins use to impinge on them. In a last part, we will discuss our current understanding of how forces are transduced into biochemical signals regulating actin dynamics in the cell through adhesive structures. 


\section{Integrin-based Adhesions and the Actin Context}

\section{$\underline{\text { Maturation of Cell Adhesions }}$}

One can distinguish three adhesion structures. The Nascent Adhesion (NA) is created at the very edge of protrusions, the Focal Complex (FC) forms in the lamellipodium width and the FA, which is an elongated structure (Fig.1). The FA is more than $1 \mu \mathrm{m}$, whereas the FC is less than $1 \mu \mathrm{m}$ long [18]. These different adhesion structures derive from one another. As the plasma membrane protrudes, the peripheral NAs first become FCs within the protrusion and subsequently FAs [19]. At one end of the spectrum, the peripheral NAs at the lamellipodial edge contains signature proteins of the lamellipodial actin network suggesting interactions with the branched actin networks that push the plasma membrane [20]. At the other end, FAs are associated with bundles of linear actin filaments. FCs are intermediate structures $[19,21]$.

NAs are characterized by a fast turnover. Their half-life is less than a minute. The ones that do not make a FC simply disassemble and disappear [22-24]. The formation of NAs and FCs depends on signaling by the small GTPases Rac1 and Cdc42, whereas the formation of FAs depends on RhoA $[25,26]$. FAs are significantly more stable with a half-life of $30 \mathrm{~min}$ [22]. Finally, FAs that do not disassemble will further mature into very stable fibrillar adhesions involved in the remodeling of ECM [18].

Adhesion initiation requires an inside-out signaling that converts integrins from a lowto a high-affinity state for ECM components (reviewed in [27]). This activation of integrins is associated with the recruitment of talin and kindlin to the integrin $\beta$-tail. Talin and kindlin- 2 are recruited to the tails of $\beta$ integrins through their FERM domain (Fig.2) [12]. Talin activates integrins through the small GTPase Rap1 and its effector RIAM [28]. Talin also makes the initial connection between ECM bound integrins and actin filaments through its $\mathrm{C}$ terminal domain $[12,29]$.

Integrins are clustered during maturation of cell adhesions, increasing the complexity of their molecular composition and connection to the actin cytoskeleton (Fig.3) [30]. Adhesion maturation requires the contractile force developed by acto-myosin [31]. FA growth 
relies on further recruitment of cytoskeletal linkers through tension-dependent exposure of cryptic binding sites [32]. For example, myosin contractility is sufficient to expose vinculin binding sites on talin [33]. Cell adhesions thus initially associate with pushing branched actin arrays and then become associated with pulling contractile actin bundles.

\section{Various Types of Stress Fibers}

A thick bundle of linear actin is usually referred to as a Stress Fiber (SF). In a SF, actin filaments are held together by cross-linking proteins, such as $\alpha$-actinins. The actin filaments are stabilized through their interaction with tropomyosins, and rendered good tracks for myosin motor activity [34]. Cells contain different types of SFs depending on their contractile properties and association to adhesion sites (Fig.1).

Thick SFs develop in between two FAs on the ventral side of the cell as a result of myosin-based contractility [35, 36]. This is under control of the RhoA pathway, which sequentially activates the Rho-kinase (ROCK) and the Myosin Light Chain Kinase [37-39]. The resulting actomyosin contractility of ventral SFs inhibits the elongation of their extremities attached to FAs, ensuring their tension [40]. Dorsal SFs are orthogonal to the leading edge and are connected to a single peripheral FA [40-43]. Although dorsal SFs are not contractile bundles, they transmit forces to FAs applied by contractile transverse arcs (TAs) $[42,44]$. These observations suggest that the force responsible for orientating dorsal SF and the elongation of their single FA is provided by TAs. Transverse arcs constitute a third SF structure, made of contractile actin, even though they are not directly connected to FAs [36, 42]. These arcs arise from myosin-induced reorganization of the lamellipodial actin network as it debranches $[42,44]$. The retrograde flow of transverse arcs may "comb" dorsal SFs through transient connections and hence exert a pulling force that elongates those dorsal SFs attached to a single FA [44, 45]. Behind the lamellipodium, at the level of the lamella, the cell is maintained flat by the tension of transverse arcs. The prominent ventral SFs originate from the myosin-based stitching of a transverse arc to two dorsal SFs, the single FA of each dorsal SF becoming the two ends of the ventral SF (Fig.1) [44].

\section{Coupling Actin Polymerization to Cell Adhesion in Protrusions}


The extension of lamellipodia during cell spreading and migration involves concomitant formation of adhesions to the underlying ECM, and later maturation and turnover of these adhesions [46-50]. In fact, membrane protrusion is required for NA formation [23]. Several studies pinpoint an essential role of Focal Adhesion Kinase (FAK) in the coupling between cell adhesion and actin polymerization [51-53].

The current model is that lamellipodial protrusions and cell adhesions are intimately coupled by feedforward and feedback mechanisms [49, 54, 55]. For continued migration, cell adhesions must initiate a membrane protrusion that will be kept adherent thanks to the generation of new NAs at the edge of the protruding lamellipodium. The cell thus 'hops' from one adhesion to the next. For efficient cell adhesion, spreading and migration, integrin binding sites located in ECM proteins should no more than 50 - $70 \mathrm{~nm}$ apart [56].

Similarly, the lifetime of a protrusion results from sustained Rac1-dependent activation of Arp2/3-mediated actin polymerization that is also subjected to feedforward and feedback regulation [5, 57]. Constant growth of actin filaments at the lamellipodial edge combined with myosin-II mediated contraction at the rear results in a global retrograde movement of the actin network $[58,59]$. The retrograde flow with respect to the plasma membrane is converted to a net forward membrane movement provided that the actin network is connected to cell adhesions (Fig.1). The coupling of actin polymerization with cell adhesions is called the molecular clutch [60].

FCs elongate into FAs in the direction of the retrograde flow at the transition between lamellipodia and lamella actin arrays [22, 23, 61]. This transition from branched actin networks to more linear arrays subjected to myosin-based contractions corresponds to a transition from a fast retrograde flow in the lamellipodia to a slower flow in the lamella [62, 63]. The slowing down of the actin retrograde flow is regarded as a consequence of the molecular clutch [23]. The force that actin polymerization exerts on integrin-mediated adhesions has been observed in the case of $\beta 3$-integrins. Using a fluid lipid bilayer to display mobile RGD peptides, RGD bound $\beta 3$-integrins were propelled by actin polymerization and clustered as a result [64]. This force sensed by $\beta 3$-integrins is likely important for the stability of FAs, since fibroblasts depleted of $\beta 3$-integrins have unstable FAs and lose directional persistence [65]. 
Cells can migrate using only lamellipodia as in fish keratocytes [66] or only filopodia [67]. Filopodia are finger-like extensions at the leading edge of migrating cells. Most often, filopodia are contained within lamellipodial protrusions, but filopodia extension is supported by linear actin arrays [68]. Interestingly, in the leading edge of the lamellipodium, $\beta 1$ integrins are clustered at the location that will give rise to a filopodium. Filopodia accumulate $\beta 1$ integrins at their tip and are thus regarded as the most advanced front of cell adhesions [69]. Filopodia can be formed independently of the Arp2/3 complex [67, 70]. But filopodia appear to guide subsequent lamellipodial protrusions [71, 72]. Similarly, cell spreading, initiated by filopodia-ECM interactions, is likely to involve integrin signaling to trigger the lamellipodia formation required to extend the cell surface [73-75].

We will now introduce the main molecular players that regulate actin polymerization with respect to cell adhesion.

\section{The Ena/VASP Elongators}

At the cell front, Ena/VASP proteins localize at all sites of active actin polymerization, whether actin is branched, as in the lamellipodial edge, or not, as in filopodia tips and FAs [76-79]. They are well established to promote the elongation of actin filaments by interacting with their barbed ends in a processive manner, and they might also nucleate new actin filaments on their own [80-83]

In the human genome, there are 3 Ena/VASP members, VASP, Mena and EVL. These 3 proteins contain the same modules, so-called Ena/VASP Homology domains, EVH1 and 2 (Fig.2). These proteins all function as tetramers and appear even more active if they are clustered onto a surface [83-85]. The EVH1 domain recruits Ena/VASP proteins to different locations depending on the exposure of FPPPP motifs [86]. The FPPPP containing proteins vinculin, zyxin, LPP, RIAM, Lamellipodin (referred to as the MRL proteins) recruit or regulate Ena/VASP proteins at the lamellipodial edge [87-92].

VASP is prominent in late FCs and mature FAs [77, 93]. Inactivation of Ena/VASP family proteins does not fully inhibit SF formation [94]. However, zyxin-VASP complexes are involved in the elongation and thickening of SFs [95] and once SFs are fully developed, they are implicated in their maintenance and repair [96]. 
The processive elongation of filament barbed ends by VASP can balance the barbed end capping activity exerted by talin and vinculin and might thus fine-tune the elongation rate of stress fibers, which in turn controls force transmission across FAs [97-99] (Fig.4A).

The amount of Ena/VASP proteins at the lamellipodial edge scales with protrusion speed [78, 82]. Counter-intuitively, protrusion speed does not translate into efficient cell migration, since high levels of Ena/VASP proteins yields decreased cell persistence [57, 94]. MRL proteins that recruit and cluster Ena/VASP proteins [100], also play a critical role in the inside-out activation of integrins as part of the Rap1-MRL-talin pathway [12]. This mechanism of integrin activation at the tip of integrin-containing filopodia creates "sticky fingers" $[71,73]$.

\section{Formins}

Formins are dimeric proteins that polymerize linear actin filaments while remaining attached to their growing barbed ends [101]. In the presence of profilin, formins tremendously speed up the elongation of actin filaments, but they can also nucleate new actin filaments [102-104]. In the human genome, the formin family is composed of 15 proteins. The diaphanous related formins (DRFs), such as mDia1 and 2, have become prototypic concerning their regulation. An intramolecular interaction between the N-terminus Diaphanous Inhibitory Domain (DID) and the C-terminus domains Diaphanous Autoregulatory Domain (DAD) is released by active Rho GTPases [105]. Different formins bind different GTPases. mDia1 is activated by RhoA, FMNL1, FMNL2, FMNL3 are activated by Cdc42, and FMNL2 and FHOD1 are regulated by Rac1 [106]. The formins mDia1, FHOD1, FMN1 and FMNL2/FMNL3 were identified among the thousands of proteins that compose the integrin adhesome [107, 108], suggesting that they can potentially be involved in the polymerization of linear actin arrays during the maturation of NAs, which depends on Rac1 and Cdc42, and later during the maturation of Fas, which depends on RhoA.

Several lines of evidence support a role for formins in the maturation of FAs, even though formins are not clearly enriched in adhesion structures. The DRF formins were the first formins identified as being involved in FA maturation and SF formation. The simultaneous activities of both mDial and the kinase ROCK, which enhances myosin-II contractility, are required for a proper organization of ventral SFs [109]. mDia1 inhibition specifically decreases the number and thickness of SFs [110]. mDial depletion was later 
shown to reduce the thickness and the velocity of actin growth from dorsal SFs, as well as the flow velocity of transverse arcs, which give rise to ventral SFs [42, 44]. In vitro, integrin complexes containing FA proteins are unable to support actin polymerization when purified from cells overexpressing the dominant negative DID domain of mDia1, unlike controls [111]. The formation of transverse arcs rather depends on mDia2 [112].

The formin FHOD1, which bundles actin filaments, plays a role in the regulation of actin dynamics and organization in NAs [113]. FHOD1 can be activated by the kinases Src and ROCK in addition to the GTPase Rac1 (Fig.4B). Src- and ROCK-mediated phosphorylations of the DAD domain decrease the affinity of the auto-inhibitory interaction [114-116]. FHOD1 is localized in the lamellipodium together with $\alpha v \beta 3$ integrin clusters in NAs [115, 117]. Inhibition of FHOD1 activity impairs cell spreading and migration because of reduced actin assembly in NAs and lower traction forces exerted by NAs [116 Gupta, 2013 \#152]. FHOD1 also accumulates in transverse arcs and growing contractile SFs [113]. Consistently, the expression of a constitutively active form of FHOD1 induces the formation of SFs [115].

In immune cells, formins are especially important. The immunological synapse is a structure that allows $\mathrm{T}$ cells to recognize antigens at the surface of antigen-presenting cells [118]. The formation of this specialized structure involves the aggregation of integrin microclusters and actin nucleation by formins in the T cell [119]. Elongation of formin-bound actin filaments could be one way of organizing integrin microclusters.

Adhesion of immune cells to the ECM also requires formins. The efficient adhesion of $\mathrm{T}$ cells to the ECM requires mDia1-mediated actin polymerization [120]. In macrophages, FMNL1, and in particular its $\gamma$ isoform, were shown to be important for the formation of podosome adhesive structures and for cell migration [121]. In neurotrophils, adhesion to fibronectin is triggered by TNF $\alpha$ stimulation and this regulated adhesion also depends on the activity of formins [122].

Formins are also involved in phagocytosis. CR3-mediated phagocytosis is mediated by the complement receptor $\mathrm{C} 3 \mathrm{ib}$, which is an integrin, the $\alpha \mathrm{M} \beta 2$ integrin. It induces a strong and fast burst of actin polymerization that depends on mDia1 activity, as well as on Arp2/3 $[123,124]$. In this process, mDial is known to have a dual role, since it couples actin polymerization to microtubules. This coupling to microtubule can be direct or indirect through CLIP170 [125], EB1 and APC [126-128]. 


\section{Interaction of the Arp2/3 complex with FA proteins}

The Arp2/3 complex is a stable multiprotein complex composed of 7 subunits, two of which are structurally related to actin, namely Arp2 and Arp3. It nucleates new actin filaments from the side of pre-existing filament, in a process called branching nucleation. In the cell, the Arp2/3 complex generates branched actin networks when activated by Nucleating Promoting Factors (NPFs). The pushing force induced by branched actin networks is critical for lamellipodial protrusions [129]. Quantitative proteomic studies of FAs have revealed the presence of the Arp2/3 complex together with subunits of the WAVE complex, a NPF that activates the Arp2/3 complex at the leading edge of the cell [108]. The Arp2/3 complex might be recruited by several FA proteins.

\section{$\underline{\text { Arp2/3 Interaction with Vinculin }}$}

The first direct interaction of the Arp2/3 complex with a FA component was reported for vinculin [20]. Vinculin is an early component of cell adhesions that is recruited by talin to NAs, as soon as tension is exerted [33, 97, 130, 131]. Vinculin is an actin filament binding protein, which thus reinforces the link between integrins and the actin cytoskeleton in response to force $[131,132]$. The binding of vinculin to talin releases an intramolecular interaction that exposes an actin binding site in the C-terminal end of vinculin (Fig.2), which blocks the barbed end elongation of actin filaments [99].

The Arp2/3 complex interacts with the so-called linker region connecting the head to the tail of vinculin (Fig.5) [20]. The linker region is invisible in the X-ray structure of autoinhibited vinculin, indicating that it is likely flexible and exposed even in the autoinhibited conformation [133]. In the cell, however, the vinculin-Arp2/3 interaction is regulated, since it is induced by EGF stimulation, which stimulates lamellipodial protrusions [20]. The mechanism regulating the interaction is not yet understood. Vinculin is not only important for FA formation, but also for lamellipodial protrusion. Consistent with an essential role of the interaction of vinculin with the Arp2/3 complex in this process, a point mutation that abrogates Arp2/3 binding renders vinculin unable to rescue the defect in lamellipodial protrusions observed in vinculin-null fibroblasts [20]. 
Purification of vinculin from tissue revealed an intriguing hybrid complex where only some subunits of the Arp2/3 complex, namely ARPC2, ARPC3, Arp2 and Arp3, were associated with vinculin [134]. The loss of ARPC1, ARPC4 and ARPC5 would render this hybrid Arp2/3 complex unable to bind pre-existing actin filaments, and so unable to induce an actin branched junction; rather the presence of vinculin might recruit the hybrid complex to cell adhesions [135]. In line with this suggestion, the depletion of ARPC1B, which is only present in canonical Arp2/3 complexes, and which is critical for lamellipodium formation [16], favors the hybrid complex and FA growth [134]. It is anticipated, but not yet formally demonstrated, that the hybrid vinculin-Arp2/3 complexes nucleate linear actin filaments. In which case, these filaments should have their pointed ends associated with the FA, suggesting that they should be antiparallel to the actin filaments, whose barbed ends abut the FA through the capping provided by talin and vinculin [98, 99]. Antiparallel filaments are perfect substrates for myosin-II to develop contractility.

In retrospect, the original interaction reported by DeMali and colleagues is compatible with the more recent discovery of the vinculin-Arp2/3 hybrid complex, because of the nature of the Arp2/3 subunits analyzed in their co-immunoprecipitations. It will be important to design ways to decipher the nature of interacting proteins in the cell, because the hybrid complex is likely to harbor a very different activity than the canonical Arp2/3 complex. The DeMali view is that a transient, regulated interaction with vinculin recruits the $\operatorname{Arp} 2 / 3$ complex to NAs and so promotes membrane protrusion [20]. The Chorev view, in contrast, is that of a stable hybrid vinculin-Arp2/3 complex, which would nucleate linear actin filaments at FAs [134].

\section{$\underline{\text { Arp2/3 Interaction with Kindlin-2 }}$}

The kindlin family of proteins binds to the $\beta$ integrin tail and activates their binding to the ECM [136-138]. The family is composed of 3 proteins (kindlin-1, kindlin-2 and kindlin-3) each containing a FERM domain (Fig.2). Kindlin FERM domains are composed of the 3 typical F1, F2 and F3 subdomains, preceded by an N-terminus F0 subdomain [139]. The F0 subdomain of kindlin-2 was shown to interact with actin filaments and to be required for cell spreading [140]. Kindlin can thus contribute to the link of NAs to the actin cytoskeleton. A characteristic feature of kindlin FERM domains is the insertion of a PH domain within the F2 
subdomain. PH domains bind to lipids and thus the $\mathrm{PH}$ domain promotes kindlin interaction with the plasma membrane $[141,142]$.

Kindlin-2 was recently reported to interact with the Arp2/3 complex (Fig.5) [143]. The binding involves the F1 subdomain of the kindlin FERM domain and in particular the arginine-100 and leucine-141 residues. In a knock-out/rescue system, a kindlin-2 form, where these two residues are substituted by alanine, is unable to support lamellipodium formation downstream of Rac1 [143]. The kindlin-Arp2/3 interaction thus appears to be required for the Arp2/3 function in powering membrane protrusions, as it was reported for the vinculinArp2/3 interaction. Interestingly, the kindlin-2 interaction with the Arp2/3 complex exists in unattached cells, suggesting that it would be an early event, perhaps allowing inactive Arp2/3 complex to be recruited at NAs when cells attach and spread. This early role does not rule out, however, a later role in the activation of the Arp2/3 complex or in the coupling of already active Arp2/3 complexes at the actin branched junctions with NAs.

\section{$\underline{\text { Arp2/3 Interaction with FAK }}$}

FAK is a non-receptor tyrosine kinase that senses cell adhesion. FAK is autoinhibited because of an intramolecular interaction that masks the kinase domain with its $\mathrm{N}$-terminal FERM domain (Fig.2). The binding of the FERM domain of FAK to the tails of engaged $\beta$ integrins relieves the autoinhibition and results in FAK autophosphorylation on the tyrosine 397 residue within the FERM domain [144]. FAK directly binds to the Arp2/3 complex through its FERM domain (Fig.5) [74]. The Arp2/3 interaction specifically involves the F1 subdomain of the FAK FERM domain, as we have already seen in the case of kindlin-2 [143, $145,146]$. As in the case of kindlin-2, FAK interacts with Arp2/3 in suspended cells and in early adherent cells, suggesting that the Arp2/3 binding site on the FERM domain is not masked by the autoinhibitory interaction of the inactive FAK. On the contrary, the interaction appears inhibited when FAK is active and autophosphorylated [74].

In a knock-out rescue system, the FAK-Arp2/3 interaction was shown to be required for lamellipodial protrusions [53]. If knock-out cells are reconstituted with mutant FAK that does not associate with the Arp2/3 complex, the formation and turn-over of NAs is defective. In this case, membrane ruffles driven by actin polymerization are formed instead of the regular lamellipodial protrusions, which require a positive feedback between membrane 
protrusions and cell adhesions. In wild type cells, active FAK interacting with integrins destabilizes NAs, promoting their turnover. On the contrary, the high density of Arp $2 / 3$ complexes in the protrusion would promote FAK-Arp2/3 interactions, resulting in FAK inactivation. Inactivating FAK would thereby promote the maturation of a fraction of stabilized NAs (Fig.5). Haptotaxis, the ability of cells to migrate up a gradient of immobilized ECM, is severely impaired when the Arp2/3 complex is inactivated or when FAK cannot interact with the Arp2/3 complex [53, 67]. Consistently, FAs are not required for cells to haptotax, but FAK signaling at NAs/FCs is [147]. Haptotaxis mediated by lamellipodial protrusions is initiated by filopodia, which orient lamellipodial extensions [72].

\section{Signaling from Integrins to Actin Polymerization}

The best established signaling pathways connecting integrins to actin polymerization involve the small GTPases Rac1 and Cdc42 [148]. In vivo, these two GTPases are key for cell migration, for example, of melanoblasts in mouse skin $[149,150]$. In addition to the formins activated by these GTPases, the Arp2/3 complex can be activated at the lamellipodial edge by the NPFs WAVE and N-WASP, respective effectors of Rac1 and Cdc42 [129]. The nonreceptor tyrosine kinase FAK is critical for NPF activation (Fig.6) [151-154]. Integrindependent auto-phosphorylation of FAK on tyrosine 397 recruits Src, which in turn phosphorylates FAK on additional tyrosine residues [155, 156].

The FAK-Src complex recruits p130Cas and phosphorylates it on multiple tyrosine residues (Fig.2) [157, 158]. Some of these phosphotyrosines represent docking sites for the SH2-containing adaptor protein Crk [158]. The p130Cas-Crk complex further recruits the Dock180-ELMO guanine exchange factor, this activates Rac1 and thus promotes lamellipodial protrusions, where FAK accumulates [159-162]. Another substrate of the FAKSrc complex is paxillin [163-165]. Paxillin is recruited to NAs through a direct interaction with kindlin-2 (Fig.6) [143, 166]. When phosphorylated on tyrosine 118, paxilllin recruits the Crk adapter, which also recruits the Dock180-ELMO guanine exchange factor [167-169]. But Paxillin also recruits the $\alpha$ - or $\beta$-PIX guanine exchange factors for Rac 1 and Cdc42 (reviewed in [170]). Paxillin is thus a critical protein for cell migration and cell invasion in Srctransformed cells [171-173]. 
The major NPF for lamellipodium formation is the WAVE protein, which is embedded into a multiprotein complex that regulates its activity (Fig.6) [174, 175]. Active Rac1 is not sufficient to activate the WAVE complex, which further requires to bind Phosphatidylinositol (3,4,5)-trisphosphate $\left(\mathrm{PIP}_{3}\right)[176,177]$. FAK directly associates with and activates Phosphatidyl Inositol 3-Kinase (PI3K) that produces $\mathrm{PIP}_{3}$ and this promotes cell migration [178, 179]. Activation of the WAVE complex depends on tyrosine and serine phosphorylations by Src and Erk MAP kinases [176, 180-183]. Interestingly, FAK also activates Erk [184, 185].

The N-WASP NPF, downstream of Cdc42, is also activated downstream of integrins, and is required for cell adhesion, migration and invasion (Fig.6) [186, 187]. N-WASP activation during early cell spreading also depends on the FAK-Src-p130Cas axis [162]. FAK is thus undoubtedly a central node connecting integrin-mediated adhesions to the polymerization of branched actin through both the Rac1-WAVE and the Cdc42-NWASP pathway.

Signaling from integrins to actin polymerization can be more direct, since the Abi1 subunit of the WAVE complex directly interacts with the tail of $\alpha 4$ integrins at the lamellipodial edge (Fig.6) [188]. $\alpha 4 \beta 1$ integrins bind to an alternatively spliced region of fibronectin, and were shown to be important for the migration of many cell types [189-192]. $\alpha 4 \beta 1$ integrins accumulate at the leading edge of lamellipodia and regulate the directionality of lamellipodial protrusions through their interaction with paxillin by phosphorylation [193, 194].

\section{Mechanotransduction}

The physical properties of the environment are sensed by the cell and trigger appropriate responses. For example, cells undergo directed migration towards stiffer substrates in a process called durotaxis and proliferate faster when they are attached to rigid substrates $[16,195]$. Because the actin cytoskeleton exerts pushing or pulling forces, through actin polymerization or actomyosin contractility respectively, it is a prime candidate to sense the physical parameters of the environment through the opposing forces this environment produces. Talin and p130Cas are two established mechanosensors. They are stretchable proteins that exposes cryptic binding sites or reveal cryptic activities upon exposure to forces. 


\section{Maturation of Adhesions in Response to Forces}

In the lamellipodium, the actin retrograde flow is thought to apply the necessary drag force that switches $\beta$ integrins into the "extended open" conformation of high affinity for ECM $[4,22,196]$. This mechanical clutch results in traction forces applied on the substratum and allows the net forward movement of the cell [132]. Talin, which connects integrin tails to the actin cytoskeleton, is stretched when myosin-II pulls on the actin cytoskeleton [33]. Talin stretching exposes vinculin binding sites [32]. Vinculin recruitment to talin reinforces the connection between cell adhesions and the actin cytoskeleton by opening up vinculin molecules, which exposes new actin binding sites [24, 33, 130, 197].

Following the formation of the mechanosensitive talin-vinculin complex, forcedependent maturation of FAs and reinforcement of adhesion develops through the further recruitment of vinculin partners, such as VASP and the actin cross-linker $\alpha$-actinin [22, 130, 198, 199]. Elongation of FAs depends on the activation of myosin-II by forces acting through RhoA, as well as the FAK-dependent phosphorylation of paxillin [25, 165]. The actin retrograde flow is mechanically coupled to the ECM by multiple layers of FA proteins that slide with respect to each other. The degree of force transmission in this sliding interface is tuned by the regulation of multiple protein interactions $[4,200,201]$.

\section{$\underline{\text { Regulation of Actin Polymerization at Force Loaded Cell Adhesions }}$}

External forces applied to SFs have been known for decades to regulate their morphology. For instance, cell stretching promotes the thickening of those SFs that reorient in the direction of the exerted force [202]. The VASP binding protein zyxin plays a central function in this mechanosensitive adaptation of SFs to mechanical cues. Zyxin recruitment to FAs is required for the thickening of SFs in response to the cyclic stretching of cells [203]. Using fluorescently labeled actin molecules, it was shown that force-dependent recruitment of zyxin to FAs coincides with the incorporation of new actin monomers into SFs at the level of FAs [204]. In agreement, laser cuts of SFs, to release the tension on FAs, accelerates zyxin detachment from FAs [205] and results in its random recruitment along the SFs [206]. Similarly, inhibiting myosin-II releases tension on FAs and prevents both zyxin recruitment and actin polymerization at FAs [204]. Zyxin is also critical to repair SFs. The high tension of SFs sometimes results in their breakage [96]. Zyxin together with VASP and $\alpha$-actinin are 
recruited to these sites and promote repair by the elongation of free barbed ends and crosslinking of actin filaments.

Formins are involved in the force-dependent actin polymerization at FAs. In a seminal experiment, a glass micropipette was used to pull on FAs, which in consequence grew in a RhoA dependent manner [31]. The expression of a constitutively active mutant of mDial lacking the RhoA binding domain rescues FA growth under load when RhoA is inhibited, suggesting that mDial is an essential effector of RhoA in this process. mDial involvement was confirmed in myoblasts, where actin polymerization was induced by applying load to beads coated with $\beta 1$ integrin ligands [207]. Interestingly, in this setting, mDia1 recruitment by the bead was visualized, whereas it is usually impossible to observe mDial recruitment at FAs. Using Atomic Force Microscopcopy (AFM) with a fibronectin coated cantilever, it was shown that formins were required for initial integrin-mediated adhesion and that a complex cross-talk between integrins containing $\alpha 5 \beta 1$ and $\alpha \mathrm{V}$ is required for adhesion to fibronectin, and its reinforcement [208].

\section{Mechanosensitive Membrane Protrusions}

Lamellipodial protrusions depend on biochemical signals, such as growth factor stimulation, but also on the stiffness of the ECM. Such membrane protrusions have only recently been recognized as mechanotransducing structures [17]. Lamellipodia formation and the ensuing responses, such as cell cycle progression on stiff substrates, are driven by cortical branched actin specifically polymerized through the activation of ARPC1B-containing Arp2/3 complexes [129]. The suppression of lamellipodial protrusions at high cell density through the inhibition of the Rac1-WAVE-Arp2/3 pathway is also the mechanism by which cell monolayers undergo so-called cell jamming at confluence, which down-regulates both cell migration and cell cycle progression [209].

Mechanotransduction from lamellipodial protrusions requires the adaptor protein p130Cas. For this function, the central substrate domain (SD) of p130Cas is critical. The SD domain binds many partners, including scaffolding molecules such as Crk, tyrosine kinases, the serine/threonine kinase JNK, GEFs and tyrosine phosphatases [210]. The SD is stretchable: upon stretching, it exposes tyrosine residues, which are normally masked, and these residues are phosphorylated by Src [211, 212]. p130Cas is a dimer, which can interact with vinculin and FAK through its N-terminal SH3 domain in nascent adhesions [213-215]. 
p130Cas is turned on by phosphorylation of tyrosine 410 in the SD domain when adhesions containing FAK and vinculin experience traction forces. p130Cas spontaneously cycles back to the off state when tyrosine 12 in the SH3 domain is phosphorylated. This prevents binding to vinculin and FAK, thus uncoupling p130Cas from adhesions experiencing pulling forces [216, 217]. Thanks to this mechanism, p130Cas mechanotransduces the initial adhesion, and then remains associated at the protruding cell edge to promote actin polymerization during cell spreading and migration [218-220].

When the SD domain of p130Cas is phosphorylated in response to stretching, it recruits Crk/C3G complexes, which subsequently activate the Rap1 GTPase and the MAP Kinase Erk [212, 221] (reviewed in [214]). Active Rap1 activates actin polymerization through the recruitment of RacGEF1, in addition to activating integrins [222].

p130Cas becomes more activated when the substrate is stiffer [220, 223]. Indeed, the Src family kinase Fyn, one of the binding partners of the p130Cas SD domain, is more active on stiffer substrates and catalyzes the phosphorylation of p130Cas [220]. If this mechanism contributes to durotaxis, it is likely not the only one. For example, slight differences in stiffness can be amplified by a positive feedback loop that involves myosin-II. Mechanodependent phosphorylation of p130Cas results in increased myosin-II activity [224], which in turn can increase the amount of unfolded phosphorylated p130Cas when the leading edge protrudes in the direction of stiffer substrates. This mechanism would explain increased Crk recruitment and Rac1-dependent lamellipodium formation in the right orientation [225].

Filopodia, which sense rigidity of the substrate, are also likely to contribute to the mechanotransduction of durotaxis. The tips of filopodia are stabilized by stiff substrates and they induce lamellipodial extensions in between them [75]. Again the mechanism requires myosin-II mediated contractility. The base of filopodia appears to be a preferred site of FA signaling [72]. Substrate stiffness is probed through pre-activated integrins at filopodium tips [71]. The ECM-integrin clutch may be stabilized by the actin retrograde flow within filopodia. Matrix rigidity sensed through filopodia is mechanotransduced through p130Cas for a fine-tuned regulation of lamellipodium formation in time and space [226].

\section{Concluding Remarks}


The major actin regulators discussed in this review are well known. Their activity has been studied in vitro and in vivo. Ena/VASP proteins are clear components of cell adhesions. In contrast, in most cases, we still do not understand at which subcellular locations formins function in adhesion-related processes. The Arp2/3 complex is a clear driver of membrane protrusions when activated by NPFs. The interactions of the Arp2/3 complex with all 3 FA components, kindlin-2, FAK and vinculin, appears to be required for membrane protrusions, but the exact role of these interactions remains to be determined. Do they positively regulate the Arp $2 / 3$ activity in protrusions? Or negatively where the actin arrays are linear? Do these interactors simply recruit the Arp $2 / 3$ complex to pass it over to the next?

It is particularly difficult to establish how precisely actin is regulated in relation to cell adhesions. Many signaling intermediates, probably the most important ones, have been identified in the last 30 years. However, understanding the functions of actin regulators and signaling intermediates in the maturation of cell adhesions, the coupling between cell adhesion and membrane protrusion and the continuous remodeling of actin arrays remain major challenges. Mechanotransduction represents a particularly intriguing case of signaling. We know now that cryptic binding sites are exposed by stretching proteins such as talin or p130Cas, and this is likely a general way to convert mechanical signals into biochemical ones. One can predict that the next major steps towards a mechanistic understanding of these events will come from elaborate in vitro reconstitutions, such as the ones where purified proteins are spatially segregated using micropatterns and temporally activated through tensile elements of the cytoskeleton.

Mechanotransduction from the substratum is the best understood case and much remain to be understood even in this favorable case. Similar mechanical interplay occurs in cell-cell junctions of coherent tissues [227]. Force mapping is more difficult in this situation where several cells are simultaneously involved [228]. Some molecular components are used in both cell-cell and cell-substratum adhesions, such as vinculin or the Arp2/3 complex. But the primary means to recruit this module differ - talin for cell-substratum adhesions, $\alpha$-catenin for cell-cell adhesions - and the force-response relationships probably also differ. More and more mechanotransduction processes involving the actin cytoskeleton are likely to emerge in the coming years. For example, when cells migrate in physically constrained environments, the induced deformation of the nucleus is an active response involving actin polymerization [229]. So the field has many exciting research avenues ahead. 


\section{$\underline{\text { Figure legends }}$}

\section{Figure 1: Relationships between integrin-based adhesions and the actin cytoskeleton.}

NAs are formed at the leading edge of the lamellipodium, where they couple branched actin networks and the ECM. As the cell migrates, NAs disassemble or elongate into FCs at the junction with the lamella. FCs further mature into FAs [18]. The elongation of non-contractile linear filaments (brown) induces filopodia when barbed ends of filaments push the plasma membrane, or dorsal SFs when barbed ends connect to FCs [230]. At the lamella/lamellipodium interface, myosin-mediated reorganization of debranching actin network results in contractile actin bundles (green). Maturation of dorsal SFs, resulting in their thickening, is based on actin polymerization and concomitant with maturation of FCs into FAs. Fusion of transverse arcs with dorsal SFs results in ventral SFs connected to FAs at each end $[42,44]$.

Figure 2: Domain organization of several FA proteins that regulate actin polymerization or perform mechanotransduction.

Domain names are in black and major binding partners are in grey. VASP: EVH1, Ena/VASP homology 1; PRD, Proline-rich domain; G, G-actin binding domain; F, F-actin binding domain; TD, tetramerization domain. Vinculin: Vh, vinculin head; D1-D4, vinculin head subdomains; D5/Vt, vinculin tail; ABD, actin binding domain. Kindlin-2: FERM, four-pointone ezrin radixin moesin; F0-F3, FERM subdomains; PH, pleckstrin homology. FAK: phosphorylated tyrosine residues are in yellow; FAT, focal adhesion targeting. Talin: IBS, integrin binding site; PTB, phosphotyrosine binding domain; 0-3, FERM subdomain F0-F3; VBS, vinculin binding site (11 VBSs are indicated in red); DD, dimerization domain. p130Cas: SH3, Src homology domain 3; SD, substrate domain (unfolded); Ser, Serine-rich domain; SBD, Src binding domain; $\mathrm{CCH}$, Cas-family C-terminal homology domain.

\section{Figure 3: Recruitment of FA proteins during FA maturation.}

The binding of activated integrins to the ECM results in the formation of NAs that further mature into FCs and FAs. Proteins that have been localized to adhesion sites (residential 
proteins) are distinguished from the associated proteins that are only known to regulate cell adhesions. The function of FA proteins is represented by colored flags.

\section{Figure 4: Polymerization of linear actin filaments downstream of integrins.}

(A) Actin elongation by VASP. In NAs and FAs, talin stretching exposes VBSs that recruit vinculin (Vinc) and activates its capping activity [97]. In mature FAs, the actin cross-linker $\alpha-$ actinin, recruited by tails of $\beta$-integrins and vinculin, induces the recruitment of zyxin. VASP is recruited both by zyxin and vinculin [87-89]. (B) Actin polymerization by the mDia1 and FHOD1 formins. mDial is activated by RhoA, which is activated in line with FA formation. FHOD1 is activated by phosphorylation events catalyzed by Src and the RhoA effector ROCK. FHOD1 is also activated by Rac1, which depends on FAK-Src signaling [231]. + and - signs respectively indicate barbed and pointed ends of actin filaments. PM: plasma membrane

\section{Figure 5: Interaction of the Arp2/3 complex with FA proteins.}

Branched actin networks of the leading edge are produced by the activation of specific Arp $2 / 3$ complexes by NPFs [16]. The Arp2/3 complex interacts with Kindlin-2, a protein that activates integrins [143]. The Arp2/3 complex interacts with FAK, a kinase that is activated by integrin-mediated adhesion $[53,74]$. The Arp2/3 complex, however, preferentially binds to the inactive conformation of FAK. The Arp2/3 complex interacts with vinculin through its linker region, which is not a cryptic binding site [20, 134]. PM: plasma membrane

\section{Figure 6: Signaling and mechanotransduction pathways that activate Arp2/3 downstream of integrins.}

Vinculin is recruited as a result of force-dependent stretching of talin. Talin bound to both the $\beta$-tail of integrins and actin filaments exposes one of the cryptic VBSs (enlargement in the left dashed circle) upon actomyosin contraction [214]. Src activates FAK bound to the $\beta$-tail of integrins, and then FAK recruits p130Cas. Dimerization of p130Cas allows mechanosensing through the anchoring of p130Cas dimers to vinculin and FAK. The tension applied on the adhesive structure unfolds the substrate domain (SD), resulting in multiple phosphorylation of p130Cas tyrosines by FAK-Src (enlargement in the right dashed circle) [214]. Alternatively, monomeric p130Cas could be mechano-activated through the binding of the C-terminal 
domain to an unknown protein [232]. The interaction of Crk with the activated SD of p130Cas in turn recruits the Guanine Exchange Factor ELMO/Dock180, which activates Rac1. Paxillin (Pax), recruited by FAK in FAs or by kindlin-2 in NAs, also recruits the CrkELMO/Dock180 complex. The activation of the WAVE complex requires binding of Rac1 to its Sra1 subunit, interaction with PIP3, formed from PIP2 by PI3K, and phosphorylation events catalyzed by Src and Erk. The N-WASP NPF is activated by the paxillin-dependent activation of $\mathrm{Cdc} 42$. Single red arrows represent phosphorylation events, double black arrows represent interactions. 


\section{Abbreviations}

ECM : ExtraCellular Matrix

NAs : Nascent Adhesions

FCs : Focal Complexes

FAs : Focal Adhesions

SFs : Stress Fibers

VBS : Vinculin Binding Site

NPFs : Nucleating Promoting Factors, i.e. Arp2/3 activators

FAK : Focal Adhesion Kinase

PI3K : Phosphatidyl Inositol 3 Kinase

PIP2 : Phospholipid phosphatidylinositol $(4,5)$-bisphosphate

PIP3 : Phosphatidylinositol (3,4,5)-trisphosphate

\section{Author contribution}

SR, CLC and AG outlined the paper. SR wrote the first draft of the manuscript and drew the figures. AG wrote the manuscript. CLC provided critical input and performed editing.

\section{Acknowledgments}

We thank Robert Kay from the MRC laboratory of Molecular Biology in Cambridge for his critical read of the manuscript and constructive suggestions.

\section{Funding information}

The work was supported by grants from the Agence Nationale de la Recherche (ANR ANR15-CE13-0016-01), from the fondation ARC pour la Recherche sur le Cancer (PGA120140200831), from Institut National du Cancer (INCA_6521) to AG and grants from the Agence Nationale de la Recherche (ANR-16-CE13-0007-02 and ANR-18-CE13-0026-01) to CLC. 


\section{Competing interests}

The Authors declare that there are no competing interests associated with the manuscript. 


\section{References}

1 DeSimone, D. W. (1994) Adhesion and matrix in vertebrate development. Curr Opin Cell Biol. 6, 747-751

2 Hynes, R. O. (2007) Cell-matrix adhesion in vascular development. J Thromb Haemost. 5 Suppl 1, 32-40

3 Vestweber, D. (2015) How leukocytes cross the vascular endothelium. Nat Rev Immunol. 15, 692-704

4 Swaminathan, V. and Waterman, C. M. (2016) The molecular clutch model for mechanotransduction evolves. Nat Cell Biol. 18, 459-461

5 Le Clainche, C. and Carlier, M. F. (2008) Regulation of actin assembly associated with protrusion and adhesion in cell migration. Physiol Rev. 88, 489-513

6 Ridley, A. J., Schwartz, M. A., Burridge, K., Firtel, R. A., Ginsberg, M. H., Borisy, G., Parsons, J. T. and Horwitz, A. R. (2003) Cell migration: integrating signals from front to back. Science. 302, 1704-1709

7 Huttenlocher, A. and Horwitz, A. R. (2011) Integrins in cell migration. Cold Spring Harb Perspect Biol. 3, a005074

8 Schwartz, M. A. and Assoian, R. K. (2001) Integrins and cell proliferation: regulation of cyclin-dependent kinases via cytoplasmic signaling pathways. J Cell Sci. 114, 2553-2560

9 Hamidi, H. and Ivaska, J. (2018) Every step of the way: integrins in cancer progression and metastasis. Nat Rev Cancer. 18, 533-548

10 Cooper, J. and Giancotti, F. G. (2019) Integrin Signaling in Cancer: Mechanotransduction, Stemness, Epithelial Plasticity, and Therapeutic Resistance. Cancer Cell. 35, 347-367

11 Bachmann, M., Kukkurainen, S., Hytonen, V. P. and Wehrle-Haller, B. (2019) Cell Adhesion by Integrins. Physiol Rev. 99, 1655-1699

12 Calderwood, D. A., Campbell, I. D. and Critchley, D. R. (2013) Talins and kindlins: partners in integrin-mediated adhesion. Nat Rev Mol Cell Biol. 14, 503-517

13 Horton, E. R., Humphries, J. D., James, J., Jones, M. C., Askari, J. A. and Humphries, M. J. (2016) The integrin adhesome network at a glance. J Cell Sci. 129, 4159-4163

14 Geiger, B., Bershadsky, A., Pankov, R. and Yamada, K. M. (2001) Transmembrane crosstalk between the extracellular matrix--cytoskeleton crosstalk. Nat Rev Mol Cell Biol. 2, 793-805

15 Panciera, T., Azzolin, L., Cordenonsi, M. and Piccolo, S. (2017) Mechanobiology of YAP and TAZ in physiology and disease. Nat Rev Mol Cell Biol. 18, 758-770

16 Molinie, N., Rubtsova, S. N., Fokin, A., Visweshwaran, S. P., Rocques, N., Polesskaya, A., Schnitzler, A., Vacher, S., Denisov, E. V., Tashireva, L. A., Perelmuter, V. M., Cherdyntseva, N. V., Bieche, I. and Gautreau, A. M. (2019) Cortical branched actin determines cell cycle progression. Cell Res. 29, 432-445

17 Oakes, P. W., Bidone, T. C., Beckham, Y., Skeeters, A. V., Ramirez-San Juan, G. R., Winter, S. P., Voth, G. A. and Gardel, M. L. (2018) Lamellipodium is a myosin-independent mechanosensor. Proc Natl Acad Sci U S A. 115, 2646-2651

18 Gardel, M. L., Schneider, I. C., Aratyn-Schaus, Y. and Waterman, C. M. (2010) Mechanical integration of actin and adhesion dynamics in cell migration. Annu Rev Cell Dev Biol. 26, 315-333

19 Izzard, C. S. and Lochner, L. R. (1980) Formation of cell-to-substrate contacts during fibroblast motility: an interference-reflexion study. J Cell Sci. 42, 81-116

20 DeMali, K. A., Barlow, C. A. and Burridge, K. (2002) Recruitment of the Arp2/3 complex to vinculin: coupling membrane protrusion to matrix adhesion. J Cell Biol. 159, 881-891 
21 Abercrombie, M., Heaysman, J. E. and Pegrum, S. M. (1971) The locomotion of fibroblasts in culture. IV. Electron microscopy of the leading lamella. Exp Cell Res. 67, 359-367

22 Choi, C. K., Vicente-Manzanares, M., Zareno, J., Whitmore, L. A., Mogilner, A. and Horwitz, A. R. (2008) Actin and alpha-actinin orchestrate the assembly and maturation of nascent adhesions in a myosin II motor-independent manner. Nat Cell Biol. 10, 1039-1050

23 Alexandrova, A. Y., Arnold, K., Schaub, S., Vasiliev, J. M., Meister, J. J., Bershadsky, A. D. and Verkhovsky, A. B. (2008) Comparative dynamics of retrograde actin flow and focal adhesions: formation of nascent adhesions triggers transition from fast to slow flow. PLoS One. 3, e3234

24 Thievessen, I., Thompson, P. M., Berlemont, S., Plevock, K. M., Plotnikov, S. V., ZemljicHarpf, A., Ross, R. S., Davidson, M. W., Danuser, G., Campbell, S. L. and Waterman, C. M. (2013) Vinculin-actin interaction couples actin retrograde flow to focal adhesions, but is dispensable for focal adhesion growth. J Cell Biol. 202, 163-177

25 Chrzanowska-Wodnicka, M. and Burridge, K. (1996) Rho-stimulated contractility drives the formation of stress fibers and focal adhesions. J Cell Biol. 133, 1403-1415

26 Nobes, C. D., Hawkins, P., Stephens, L. and Hall, A. (1995) Activation of the small GTPbinding proteins rho and rac by growth factor receptors. J Cell Sci. 108 ( Pt 1), 225-233

27 Shattil, S. J., Kim, C. and Ginsberg, M. H. (2010) The final steps of integrin activation: the end game. Nat Rev Mol Cell Biol. 11, 288-300

28 Han, J., Lim, C. J., Watanabe, N., Soriani, A., Ratnikov, B., Calderwood, D. A., PuzonMcLaughlin, W., Lafuente, E. M., Boussiotis, V. A., Shattil, S. J. and Ginsberg, M. H. (2006) Reconstructing and deconstructing agonist-induced activation of integrin alphaIIbbeta3. Curr Biol. 16, 1796-1806

29 Jiang, G., Giannone, G., Critchley, D. R., Fukumoto, E. and Sheetz, M. P. (2003) Twopiconewton slip bond between fibronectin and the cytoskeleton depends on talin. Nature. 424, 334-337

30 Geiger, B., Spatz, J. P. and Bershadsky, A. D. (2009) Environmental sensing through focal adhesions. Nat Rev Mol Cell Biol. 10, 21-33

31 Riveline, D., Zamir, E., Balaban, N. Q., Schwarz, U. S., Ishizaki, T., Narumiya, S., Kam, Z., Geiger, B. and Bershadsky, A. D. (2001) Focal contacts as mechanosensors: externally applied local mechanical force induces growth of focal contacts by an mDia1-dependent and ROCK-independent mechanism. J Cell Biol. 153, 1175-1186

32 del Rio, A., Perez-Jimenez, R., Liu, R., Roca-Cusachs, P., Fernandez, J. M. and Sheetz, M. P. (2009) Stretching single talin rod molecules activates vinculin binding. Science. 323, 638-641

33 Ciobanasu, C., Faivre, B. and Le Clainche, C. (2014) Actomyosin-dependent formation of the mechanosensitive talin-vinculin complex reinforces actin anchoring. Nat Commun. 5, 3095

34 Pellegrin, S. and Mellor, H. (2007) Actin stress fibres. J Cell Sci. 120, 3491-3499

35 Burridge, K. and Chrzanowska-Wodnicka, M. (1996) Focal adhesions, contractility, and signaling. Annu Rev Cell Dev Biol. 12, 463-518

36 Small, J. V., Rottner, K., Kaverina, I. and Anderson, K. I. (1998) Assembling an actin cytoskeleton for cell attachment and movement. Biochim Biophys Acta. 1404, 271-281

37 Fujisawa, K., Fujita, A., Ishizaki, T., Saito, Y. and Narumiya, S. (1996) Identification of the Rho-binding domain of p160ROCK, a Rho-associated coiled-coil containing protein kinase. J Biol Chem. 271, 23022-23028

38 Ridley, A. J. and Hall, A. (1992) The small GTP-binding protein rho regulates the assembly of focal adhesions and actin stress fibers in response to growth factors. Cell. 70, 389-399 
39 Totsukawa, G., Yamakita, Y., Yamashiro, S., Hartshorne, D. J., Sasaki, Y. and Matsumura, F. (2000) Distinct roles of ROCK (Rho-kinase) and MLCK in spatial regulation of MLC phosphorylation for assembly of stress fibers and focal adhesions in 3 T3 fibroblasts. J Cell Biol. 150, 797-806

40 Tojkander, S., Gateva, G., Husain, A., Krishnan, R. and Lappalainen, P. (2015) Generation of contractile actomyosin bundles depends on mechanosensitive actin filament assembly and disassembly. Elife. 4, e06126

41 Endlich, N., Otey, C. A., Kriz, W. and Endlich, K. (2007) Movement of stress fibers away from focal adhesions identifies focal adhesions as sites of stress fiber assembly in stationary cells. Cell Motil Cytoskeleton. 64, 966-976

42 Hotulainen, P. and Lappalainen, P. (2006) Stress fibers are generated by two distinct actin assembly mechanisms in motile cells. J Cell Biol. 173, 383-394

43 Russell, R. J., Grubbs, A. Y., Mangroo, S. P., Nakasone, S. E., Dickinson, R. B. and Lele, T. P. (2011) Sarcomere length fluctuations and flow in capillary endothelial cells. Cytoskeleton (Hoboken). 68, 150-156

44 Burnette, D. T., Shao, L., Ott, C., Pasapera, A. M., Fischer, R. S., Baird, M. A., Der Loughian, C., Delanoe-Ayari, H., Paszek, M. J., Davidson, M. W., Betzig, E. and Lippincott-Schwartz, J. (2014) A contractile and counterbalancing adhesion system controls the 3D shape of crawling cells. J Cell Biol. 205, 83-96

45 Nagayama, K., Adachi, A. and Matsumoto, T. (2011) Heterogeneous response of traction force at focal adhesions of vascular smooth muscle cells subjected to macroscopic stretch on a micropillar substrate. J Biomech. 44, 2699-2705

46 Devreotes, P. and Horwitz, A. R. (2015) Signaling networks that regulate cell migration. Cold Spring Harb Perspect Biol. 7, a005959

47 Petrie, R. J., Doyle, A. D. and Yamada, K. M. (2009) Random versus directionally persistent cell migration. Nat Rev Mol Cell Biol. 10, 538-549

48 Giannone, G., Dubin-Thaler, B. J., Dobereiner, H. G., Kieffer, N., Bresnick, A. R. and Sheetz, M. P. (2004) Periodic lamellipodial contractions correlate with rearward actin waves. Cell. 116, 431443

49 Gupton, S. L. and Waterman-Storer, C. M. (2006) Spatiotemporal feedback between actomyosin and focal-adhesion systems optimizes rapid cell migration. Cell. 125, 1361-1374

50 Schneider, I. C., Hays, C. K. and Waterman, C. M. (2009) Epidermal growth factor-induced contraction regulates paxillin phosphorylation to temporally separate traction generation from deadhesion. Mol Biol Cell. 20, 3155-3167

51 Choi, C. K., Zareno, J., Digman, M. A., Gratton, E. and Horwitz, A. R. (2011) Crosscorrelated fluctuation analysis reveals phosphorylation-regulated paxillin-FAK complexes in nascent adhesions. Biophys J. 100, 583-592

52 Lawson, C. and Schlaepfer, D. D. (2012) Integrin adhesions: who's on first? What's on second? Connections between FAK and talin. Cell Adh Migr. 6, 302-306

53 Swaminathan, V., Fischer, R. S. and Waterman, C. M. (2016) The FAK-Arp2/3 interaction promotes leading edge advance and haptosensing by coupling nascent adhesions to lamellipodia actin. Mol Biol Cell. 27, 1085-1100

54 Machacek, M., Hodgson, L., Welch, C., Elliott, H., Pertz, O., Nalbant, P., Abell, A., Johnson, G. L., Hahn, K. M. and Danuser, G. (2009) Coordination of Rho GTPase activities during cell protrusion. Nature. 461, 99-103

55 Mitra, S. K., Hanson, D. A. and Schlaepfer, D. D. (2005) Focal adhesion kinase: in command and control of cell motility. Nat Rev Mol Cell Biol. 6, 56-68 
56 Selhuber-Unkel, C., Erdmann, T., Lopez-Garcia, M., Kessler, H., Schwarz, U. S. and Spatz, J. P. (2010) Cell adhesion strength is controlled by intermolecular spacing of adhesion receptors. Biophys J. 98, 543-551

57 Krause, M. and Gautreau, A. (2014) Steering cell migration: lamellipodium dynamics and the regulation of directional persistence. Nat Rev Mol Cell Biol. 15, 577-590

58 Gardel, M. L., Sabass, B., Ji, L., Danuser, G., Schwarz, U. S. and Waterman, C. M. (2008) Traction stress in focal adhesions correlates biphasically with actin retrograde flow speed. J Cell Biol. 183, 999-1005

59 Lin, C. H. and Forscher, P. (1995) Growth cone advance is inversely proportional to retrograde F-actin flow. Neuron. 14, 763-771

60 Case, L. B. and Waterman, C. M. (2015) Integration of actin dynamics and cell adhesion by a three-dimensional, mechanosensitive molecular clutch. Nat Cell Biol. 17, 955-963

61 Oakes, P. W., Beckham, Y., Stricker, J. and Gardel, M. L. (2012) Tension is required but not sufficient for focal adhesion maturation without a stress fiber template. J Cell Biol. 196, 363-374

62 Burnette, D. T., Manley, S., Sengupta, P., Sougrat, R., Davidson, M. W., Kachar, B. and Lippincott-Schwartz, J. (2011) A role for actin arcs in the leading-edge advance of migrating cells. Nat Cell Biol. 13, 371-381

63 Ponti, A., Machacek, M., Gupton, S. L., Waterman-Storer, C. M. and Danuser, G. (2004) Two distinct actin networks drive the protrusion of migrating cells. Science. 305, 1782-1786

64 Yu, C. H., Law, J. B., Suryana, M., Low, H. Y. and Sheetz, M. P. (2011) Early integrin binding to Arg-Gly-Asp peptide activates actin polymerization and contractile movement that stimulates outward translocation. Proc Natl Acad Sci U S A. 108, 20585-20590

65 Worth, D. C., Hodivala-Dilke, K., Robinson, S. D., King, S. J., Morton, P. E., Gertler, F. B., Humphries, M. J. and Parsons, M. (2010) Alpha v beta3 integrin spatially regulates VASP and RIAM to control adhesion dynamics and migration. J Cell Biol. 189, 369-383

66 Keren, K., Pincus, Z., Allen, G. M., Barnhart, E. L., Marriott, G., Mogilner, A. and Theriot, J. A. (2008) Mechanism of shape determination in motile cells. Nature. 453, 475-480

67 Wu, C., Asokan, S. B., Berginski, M. E., Haynes, E. M., Sharpless, N. E., Griffith, J. D., Gomez, S. M. and Bear, J. E. (2012) Arp2/3 is critical for lamellipodia and response to extracellular matrix cues but is dispensable for chemotaxis. Cell. 148, 973-987

68 Medalia, O., Beck, M., Ecke, M., Weber, I., Neujahr, R., Baumeister, W. and Gerisch, G. (2007) Organization of actin networks in intact filopodia. Curr Biol. 17, 79-84

69 Galbraith, C. G., Yamada, K. M. and Galbraith, J. A. (2007) Polymerizing actin fibers position integrins primed to probe for adhesion sites. Science. 315, 992-995

70 Steffen, A., Faix, J., Resch, G. P., Linkner, J., Wehland, J., Small, J. V., Rottner, K. and Stradal, T. E. (2006) Filopodia formation in the absence of functional WAVE- and Arp2/3-complexes. Mol Biol Cell. 17, 2581-2591

71 Lagarrigue, F., Vikas Anekal, P., Lee, H. S., Bachir, A. I., Ablack, J. N., Horwitz, A. F. and Ginsberg, M. H. (2015) A RIAM/lamellipodin-talin-integrin complex forms the tip of sticky fingers that guide cell migration. Nat Commun. 6, 8492

72 Johnson, H. E., King, S. J., Asokan, S. B., Rotty, J. D., Bear, J. E. and Haugh, J. M. (2015) Factin bundles direct the initiation and orientation of lamellipodia through adhesion-based signaling. $\mathbf{J}$ Cell Biol. 208, 443-455

73 Partridge, M. A. and Marcantonio, E. E. (2006) Initiation of attachment and generation of mature focal adhesions by integrin-containing filopodia in cell spreading. Mol Biol Cell. 17, 42374248 
74 Serrels, B., Serrels, A., Brunton, V. G., Holt, M., McLean, G. W., Gray, C. H., Jones, G. E. and Frame, M. C. (2007) Focal adhesion kinase controls actin assembly via a FERM-mediated interaction with the Arp2/3 complex. Nat Cell Biol. 9, 1046-1056

75 Wong, S., Guo, W. H. and Wang, Y. L. (2014) Fibroblasts probe substrate rigidity with filopodia extensions before occupying an area. Proc Natl Acad Sci U S A. 111, 17176-17181

76 Gertler, F. B., Niebuhr, K., Reinhard, M., Wehland, J. and Soriano, P. (1996) Mena, a relative of VASP and Drosophila Enabled, is implicated in the control of microfilament dynamics. Cell. 87, 227-239

77 Reinhard, M., Halbrugge, M., Scheer, U., Wiegand, C., Jockusch, B. M. and Walter, U. (1992) The 46/50 kDa phosphoprotein VASP purified from human platelets is a novel protein associated with actin filaments and focal contacts. EMBO J. 11, 2063-2070

78 Rottner, K., Behrendt, B., Small, J. V. and Wehland, J. (1999) VASP dynamics during lamellipodia protrusion. Nat Cell Biol. 1, 321-322

79 Svitkina, T. M., Bulanova, E. A., Chaga, O. Y., Vignjevic, D. M., Kojima, S., Vasiliev, J. M. and Borisy, G. G. (2003) Mechanism of filopodia initiation by reorganization of a dendritic network. J Cell Biol. 160, 409-421

80 Laurent, V., Loisel, T. P., Harbeck, B., Wehman, A., Grobe, L., Jockusch, B. M., Wehland, J., Gertler, F. B. and Carlier, M. F. (1999) Role of proteins of the Ena/VASP family in actin-based motility of Listeria monocytogenes. J Cell Biol. 144, 1245-1258

81 Barzik, M., Kotova, T. I., Higgs, H. N., Hazelwood, L., Hanein, D., Gertler, F. B. and Schafer, D. A. (2005) Ena/VASP proteins enhance actin polymerization in the presence of barbed end capping proteins. J Biol Chem. 280, 28653-28662

82 Bear, J. E., Svitkina, T. M., Krause, M., Schafer, D. A., Loureiro, J. J., Strasser, G. A., Maly, I. V., Chaga, O. Y., Cooper, J. A., Borisy, G. G. and Gertler, F. B. (2002) Antagonism between Ena/VASP proteins and actin filament capping regulates fibroblast motility. Cell. 109, 509-521

83 Breitsprecher, D., Kiesewetter, A. K., Linkner, J., Urbanke, C., Resch, G. P., Small, J. V. and Faix, J. (2008) Clustering of VASP actively drives processive, WH2 domain-mediated actin filament elongation. EMBO J. 27, 2943-2954

84 Bruhmann, S., Ushakov, D. S., Winterhoff, M., Dickinson, R. B., Curth, U. and Faix, J. (2017) Distinct VASP tetramers synergize in the processive elongation of individual actin filaments from clustered arrays. Proc Natl Acad Sci U S A. 114, E5815-E5824

85 Hansen, S. D. and Mullins, R. D. (2010) VASP is a processive actin polymerase that requires monomeric actin for barbed end association. J Cell Biol. 191, 571-584

86 Prehoda, K. E., Lee, D. J. and Lim, W. A. (1999) Structure of the enabled/VASP homology 1 domain-peptide complex: a key component in the spatial control of actin assembly. Cell. 97, 471-480

87 Brindle, N. P., Holt, M. R., Davies, J. E., Price, C. J. and Critchley, D. R. (1996) The focaladhesion vasodilator-stimulated phosphoprotein (VASP) binds to the proline-rich domain in vinculin. Biochem J. 318 ( Pt 3), 753-757

88 Reinhard, M., Rudiger, M., Jockusch, B. M. and Walter, U. (1996) VASP interaction with vinculin: a recurring theme of interactions with proline-rich motifs. FEBS Lett. 399, 103-107

89 Drees, B., Friederich, E., Fradelizi, J., Louvard, D., Beckerle, M. C. and Golsteyn, R. M. (2000) Characterization of the interaction between zyxin and members of the Ena/vasodilatorstimulated phosphoprotein family of proteins. J Biol Chem. 275, 22503-22511

90 Petit, M. M., Fradelizi, J., Golsteyn, R. M., Ayoubi, T. A., Menichi, B., Louvard, D., Van de Ven, W. J. and Friederich, E. (2000) LPP, an actin cytoskeleton protein related to zyxin, harbors a nuclear export signal and transcriptional activation capacity. Mol Biol Cell. 11, 117-129 
91 Krause, M., Leslie, J. D., Stewart, M., Lafuente, E. M., Valderrama, F., Jagannathan, R., Strasser, G. A., Rubinson, D. A., Liu, H., Way, M., Yaffe, M. B., Boussiotis, V. A. and Gertler, F. B. (2004) Lamellipodin, an Ena/VASP ligand, is implicated in the regulation of lamellipodial dynamics. Dev Cell. 7, 571-583

92 Lafuente, E. M., van Puijenbroek, A. A., Krause, M., Carman, C. V., Freeman, G. J., Berezovskaya, A., Constantine, E., Springer, T. A., Gertler, F. B. and Boussiotis, V. A. (2004) RIAM, an Ena/VASP and Profilin ligand, interacts with Rap1-GTP and mediates Rap1-induced adhesion. Dev Cell. 7, 585-595

93 Loureiro, J. J., Rubinson, D. A., Bear, J. E., Baltus, G. A., Kwiatkowski, A. V. and Gertler, F. B. (2002) Critical roles of phosphorylation and actin binding motifs, but not the central proline-rich region, for Ena/vasodilator-stimulated phosphoprotein (VASP) function during cell migration. Mol Biol Cell. 13, 2533-2546

94 Bear, J. E., Loureiro, J. J., Libova, I., Fassler, R., Wehland, J. and Gertler, F. B. (2000) Negative regulation of fibroblast motility by Ena/VASP proteins. Cell. 101, 717-728

95 Fradelizi, J., Noireaux, V., Plastino, J., Menichi, B., Louvard, D., Sykes, C., Golsteyn, R. M. and Friederich, E. (2001) ActA and human zyxin harbour Arp2/3-independent actin-polymerization activity. Nat Cell Biol. 3, 699-707

96 Smith, M. A., Blankman, E., Gardel, M. L., Luettjohann, L., Waterman, C. M. and Beckerle, M. C. (2010) A zyxin-mediated mechanism for actin stress fiber maintenance and repair. Dev Cell. 19, 365-376

97 Ciobanasu, C., Faivre, B. and Le Clainche, C. (2013) Integrating actin dynamics, mechanotransduction and integrin activation: the multiple functions of actin binding proteins in focal adhesions. Eur J Cell Biol. 92, 339-348

98 Ciobanasu, C., Wang, H., Henriot, V., Mathieu, C., Fente, A., Csillag, S., Vigouroux, C., Faivre, B. and Le Clainche, C. (2018) Integrin-bound talin head inhibits actin filament barbed-end elongation. J Biol Chem. 293, 2586-2596

99 Le Clainche, C., Dwivedi, S. P., Didry, D. and Carlier, M. F. (2010) Vinculin is a dually regulated actin filament barbed end-capping and side-binding protein. J Biol Chem. 285, 23420-23432

100 Hansen, S. D. and Mullins, R. D. (2015) Lamellipodin promotes actin assembly by clustering Ena/VASP proteins and tethering them to actin filaments. Elife. 4

101 Paul, A. S. and Pollard, T. D. (2009) Review of the mechanism of processive actin filament elongation by formins. Cell Motil Cytoskeleton. 66, 606-617

102 Evangelista, M., Pruyne, D., Amberg, D. C., Boone, C. and Bretscher, A. (2002) Formins direct Arp2/3-independent actin filament assembly to polarize cell growth in yeast. Nat Cell Biol. 4, $32-41$

103 Kovar, D. R., Harris, E. S., Mahaffy, R., Higgs, H. N. and Pollard, T. D. (2006) Control of the assembly of ATP- and ADP-actin by formins and profilin. Cell. 124, 423-435

104 Romero, S., Le Clainche, C., Didry, D., Egile, C., Pantaloni, D. and Carlier, M. F. (2004) Formin is a processive motor that requires profilin to accelerate actin assembly and associated ATP hydrolysis. Cell. 119, 419-429

105 Li, F. and Higgs, H. N. (2003) The mouse Formin mDia1 is a potent actin nucleation factor regulated by autoinhibition. Curr Biol. 13, 1335-1340

106 Kuhn, S. and Geyer, M. (2014) Formins as effector proteins of Rho GTPases. Small GTPases. 5, e29513

107 Schiller, H. B., Friedel, C. C., Boulegue, C. and Fassler, R. (2011) Quantitative proteomics of the integrin adhesome show a myosin II-dependent recruitment of LIM domain proteins. EMBO Rep. 12, 259-266 
108 Horton, E. R., Byron, A., Askari, J. A., Ng, D. H. J., Millon-Fremillon, A., Robertson, J., Koper, E. J., Paul, N. R., Warwood, S., Knight, D., Humphries, J. D. and Humphries, M. J. (2015) Definition of a consensus integrin adhesome and its dynamics during adhesion complex assembly and disassembly. Nat Cell Biol. 17, 1577-1587

109 Watanabe, N., Kato, T., Fujita, A., Ishizaki, T. and Narumiya, S. (1999) Cooperation between mDia1 and ROCK in Rho-induced actin reorganization. Nat Cell Biol. 1, 136-143

110 Tominaga, T., Sahai, E., Chardin, P., McCormick, F., Courtneidge, S. A. and Alberts, A. S. (2000) Diaphanous-related formins bridge Rho GTPase and Src tyrosine kinase signaling. Mol Cell. 5, $13-25$

111 Butler, B., Gao, C., Mersich, A. T. and Blystone, S. D. (2006) Purified integrin adhesion complexes exhibit actin-polymerization activity. Curr Biol. 16, 242-251

112 Tojkander, S., Gateva, G., Schevzov, G., Hotulainen, P., Naumanen, P., Martin, C., Gunning, P. W. and Lappalainen, P. (2011) A molecular pathway for myosin II recruitment to stress fibers. Curr Biol. 21, 539-550

113 Schonichen, A., Mannherz, H. G., Behrmann, E., Mazur, A. J., Kuhn, S., Silvan, U., Schoenenberger, C. A., Fackler, O. T., Raunser, S., Dehmelt, L. and Geyer, M. (2013) FHOD1 is a combined actin filament capping and bundling factor that selectively associates with actin arcs and stress fibers. J Cell Sci. 126, 1891-1901

114 Takeya, R., Taniguchi, K., Narumiya, S. and Sumimoto, H. (2008) The mammalian formin FHOD1 is activated through phosphorylation by ROCK and mediates thrombin-induced stress fibre formation in endothelial cells. EMBO J. 27, 618-628

115 Koka, S., Minick, G. T., Zhou, Y., Westendorf, J. J. and Boehm, M. B. (2005) Src regulates the activity of the mammalian formin protein FHOD1. Biochem Biophys Res Commun. 336, 12851291

116 Iskratsch, T., Yu, C. H., Mathur, A., Liu, S., Stevenin, V., Dwyer, J., Hone, J., Ehler, E. and Sheetz, M. (2013) FHOD1 is needed for directed forces and adhesion maturation during cell spreading and migration. Dev Cell. 27, 545-559

117 Gupta, P., Gauthier, N. C., Cheng-Han, Y., Zuanning, Y., Pontes, B., Ohmstede, M., Martin, R., Knolker, H. J., Dobereiner, H. G., Krendel, M. and Sheetz, M. (2013) Myosin 1E localizes to actin polymerization sites in lamellipodia, affecting actin dynamics and adhesion formation. Biol Open. 2, 1288-1299

118 Beemiller, P. and Krummel, M. F. (2013) Regulation of T-cell receptor signaling by the actin cytoskeleton and poroelastic cytoplasm. Immunol Rev. 256, 148-159

119 Murugesan, S., Hong, J., Yi, J., Li, D., Beach, J. R., Shao, L., Meinhardt, J., Madison, G., Wu, X., Betzig, E. and Hammer, J. A. (2016) Formin-generated actomyosin arcs propel T cell receptor microcluster movement at the immune synapse. J Cell Biol. 215, 383-399

120 Eisenmann, K. M., Harris, E. S., Kitchen, S. M., Holman, H. A., Higgs, H. N. and Alberts, A. S. (2007) Dia-interacting protein modulates formin-mediated actin assembly at the cell cortex. Curr Biol. 17, 579-591

121 Miller, M. R., Miller, E. W. and Blystone, S. D. (2017) Non-canonical activity of the podosomal formin FMNL1gamma supports immune cell migration. J Cell Sci. 130, 1730-1739

122 Silveira, A. A. A., Dominical, V. M., Almeida, C. B., Chweih, H., Ferreira, W. A., Jr., Vicente, C. P., Costa, F. T. M., Werneck, C. C., Costa, F. F. and Conran, N. (2018) TNF induces neutrophil adhesion via formin-dependent cytoskeletal reorganization and activation of beta-integrin function. J Leukoc Biol. 103, 87-98

123 Colucci-Guyon, E., Niedergang, F., Wallar, B. J., Peng, J., Alberts, A. S. and Chavrier, P. (2005) A role for mammalian diaphanous-related formins in complement receptor (CR3)-mediated phagocytosis in macrophages. Curr Biol. 15, 2007-2012 
124 Rotty, J. D., Brighton, H. E., Craig, S. L., Asokan, S. B., Cheng, N., Ting, J. P. and Bear, J. E. (2017) Arp2/3 Complex Is Required for Macrophage Integrin Functions but Is Dispensable for FcR Phagocytosis and In Vivo Motility. Dev Cell. 42, 498-513 e496

125 Lewkowicz, E., Herit, F., Le Clainche, C., Bourdoncle, P., Perez, F. and Niedergang, F. (2008) The microtubule-binding protein CLIP-170 coordinates mDia1 and actin reorganization during CR3-mediated phagocytosis. J Cell Biol. 183, 1287-1298

126 Bartolini, F., Moseley, J. B., Schmoranzer, J., Cassimeris, L., Goode, B. L. and Gundersen, G. G. (2008) The formin mDia2 stabilizes microtubules independently of its actin nucleation activity. J Cell Biol. 181, 523-536

127 Gaillard, J., Ramabhadran, V., Neumanne, E., Gurel, P., Blanchoin, L., Vantard, M. and Higgs, H. N. (2011) Differential interactions of the formins INF2, mDia1, and mDia2 with microtubules. Mol Biol Cell. 22, 4575-4587

128 Wen, Y., Eng, C. H., Schmoranzer, J., Cabrera-Poch, N., Morris, E. J., Chen, M., Wallar, B. J., Alberts, A. S. and Gundersen, G. G. (2004) EB1 and APC bind to mDia to stabilize microtubules downstream of Rho and promote cell migration. Nat Cell Biol. 6, 820-830

129 Molinie, N. and Gautreau, A. (2018) The Arp2/3 Regulatory System and Its Deregulation in Cancer. Physiol Rev. 98, 215-238

130 Atherton, P., Stutchbury, B., Wang, D. Y., Jethwa, D., Tsang, R., Meiler-Rodriguez, E., Wang, P., Bate, N., Zent, R., Barsukov, I. L., Goult, B. T., Critchley, D. R. and Ballestrem, C. (2015) Vinculin controls talin engagement with the actomyosin machinery. Nat Commun. 6, 10038

131 Atherton, P., Stutchbury, B., Jethwa, D. and Ballestrem, C. (2016) Mechanosensitive components of integrin adhesions: Role of vinculin. Exp Cell Res. 343, 21-27

132 Wolfenson, H., Lavelin, I. and Geiger, B. (2013) Dynamic regulation of the structure and functions of integrin adhesions. Dev Cell. 24, 447-458

133 Bakolitsa, C., Cohen, D. M., Bankston, L. A., Bobkov, A. A., Cadwell, G. W., Jennings, L., Critchley, D. R., Craig, S. W. and Liddington, R. C. (2004) Structural basis for vinculin activation at sites of cell adhesion. Nature. 430, 583-586

134 Chorev, D. S., Moscovitz, O., Geiger, B. and Sharon, M. (2014) Regulation of focal adhesion formation by a vinculin-Arp2/3 hybrid complex. Nat Commun. 5, 3758

135 Pizarro-Cerda, J., Chorev, D. S., Geiger, B. and Cossart, P. (2017) The Diverse Family of Arp2/3 Complexes. Trends Cell Biol. 27, 93-100

136 Dowling, J. J., Vreede, A. P., Kim, S., Golden, J. and Feldman, E. L. (2008) Kindlin-2 is required for myocyte elongation and is essential for myogenesis. BMC Cell Biol. 9, 36

137 Ma, Y. Q., Qin, J., Wu, C. and Plow, E. F. (2008) Kindlin-2 (Mig-2): a co-activator of beta3 integrins. J Cell Biol. 181, 439-446

138 Meves, A., Stremmel, C., Gottschalk, K. and Fassler, R. (2009) The Kindlin protein family: new members to the club of focal adhesion proteins. Trends Cell Biol. 19, 504-513

139 Malinin, N. L., Plow, E. F. and Byzova, T. V. (2010) Kindlins in FERM adhesion. Blood. 115, 4011-4017

140 Bledzka, K., Bialkowska, K., Sossey-Alaoui, K., Vaynberg, J., Pluskota, E., Qin, J. and Plow, E. F. (2016) Kindlin-2 directly binds actin and regulates integrin outside-in signaling. J Cell Biol. 213, $97-108$

141 Liu, J., Fukuda, K., Xu, Z., Ma, Y. Q., Hirbawi, J., Mao, X., Wu, C., Plow, E. F. and Qin, J. (2011) Structural basis of phosphoinositide binding to kindlin-2 protein pleckstrin homology domain in regulating integrin activation. J Biol Chem. 286, 43334-43342 
142 Liu, Y., Zhu, Y., Ye, S. and Zhang, R. (2012) Crystal structure of kindlin-2 PH domain reveals a conformational transition for its membrane anchoring and regulation of integrin activation. Protein Cell. 3, 434-440

143 Bottcher, R. T., Veelders, M., Rombaut, P., Faix, J., Theodosiou, M., Stradal, T. E., Rottner, K., Zent, R., Herzog, F. and Fassler, R. (2017) Kindlin-2 recruits paxillin and Arp2/3 to promote membrane protrusions during initial cell spreading. J Cell Biol. 216, 3785-3798

144 Zhao, X. and Guan, J. L. (2011) Focal adhesion kinase and its signaling pathways in cell migration and angiogenesis. Adv Drug Deliv Rev. 63, 610-615

145 Kammerer, P., Aretz, J. and Fassler, R. (2017) Lucky kindlin: A cloverleaf at the integrin tail. Proc Natl Acad Sci U S A. 114, 9234-9236

146 Li, H., Deng, Y., Sun, K., Yang, H., Liu, J., Wang, M., Zhang, Z., Lin, J., Wu, C., Wei, Z. and $\mathrm{Yu}, \mathrm{C}$. (2017) Structural basis of kindlin-mediated integrin recognition and activation. Proc Natl Acad Sci U S A. 114, 9349-9354

147 King, S. J., Asokan, S. B., Haynes, E. M., Zimmerman, S. P., Rotty, J. D., Alb, J. G., Jr., Tagliatela, A., Blake, D. R., Lebedeva, I. P., Marston, D., Johnson, H. E., Parsons, M., Sharpless, N. E., Kuhlman, B., Haugh, J. M. and Bear, J. E. (2016) Lamellipodia are crucial for haptotactic sensing and response. J Cell Sci. 129, 2329-2342

148 Price, L. S., Leng, J., Schwartz, M. A. and Bokoch, G. M. (1998) Activation of Rac and Cdc42 by integrins mediates cell spreading. Mol Biol Cell. 9, 1863-1871

149 Li, A., Ma, Y., Yu, X., Mort, R. L., Lindsay, C. R., Stevenson, D., Strathdee, D., Insall, R. H., Chernoff, J., Snapper, S. B., Jackson, I. J., Larue, L., Sansom, O. J. and Machesky, L. M. (2011) Rac1 drives melanoblast organization during mouse development by orchestrating pseudopod- driven motility and cell-cycle progression. Dev Cell. 21, 722-734

150 Woodham, E. F., Paul, N. R., Tyrrell, B., Spence, H. J., Swaminathan, K., Scribner, M. R., Giampazolias, E., Hedley, A., Clark, W., Kage, F., Marston, D. J., Hahn, K. M., Tait, S. W., Larue, L., Brakebusch, C. H., Insall, R. H. and Machesky, L. M. (2017) Coordination by Cdc42 of Actin, Contractility, and Adhesion for Melanoblast Movement in Mouse Skin. Curr Biol. 27, 624-637

151 Tilghman, R. W., Slack-Davis, J. K., Sergina, N., Martin, K. H., Iwanicki, M., Hershey, E. D., Beggs, H. E., Reichardt, L. F. and Parsons, J. T. (2005) Focal adhesion kinase is required for the spatial organization of the leading edge in migrating cells. J Cell Sci. 118, 2613-2623

152 Owen, K. A., Pixley, F. J., Thomas, K. S., Vicente-Manzanares, M., Ray, B. J., Horwitz, A. F., Parsons, J. T., Beggs, H. E., Stanley, E. R. and Bouton, A. H. (2007) Regulation of lamellipodial persistence, adhesion turnover, and motility in macrophages by focal adhesion kinase. J Cell Biol. 179, $1275-1287$

153 Chan, K. T., Bennin, D. A. and Huttenlocher, A. (2010) Regulation of adhesion dynamics by calpain-mediated proteolysis of focal adhesion kinase (FAK). J Biol Chem. 285, 11418-11426

154 Ezratty, E. J., Partridge, M. A. and Gundersen, G. G. (2005) Microtubule-induced focal adhesion disassembly is mediated by dynamin and focal adhesion kinase. Nat Cell Biol. 7, 581-590

155 Lietha, D., Cai, X., Ceccarelli, D. F., Li, Y., Schaller, M. D. and Eck, M. J. (2007) Structural basis for the autoinhibition of focal adhesion kinase. Cell. 129, 1177-1187

156 Frame, M. C., Patel, H., Serrels, B., Lietha, D. and Eck, M. J. (2010) The FERM domain: organizing the structure and function of FAK. Nat Rev Mol Cell Biol. 11, 802-814

157 Polte, T. R. and Hanks, S. K. (1995) Interaction between focal adhesion kinase and Crkassociated tyrosine kinase substrate p130Cas. Proc Natl Acad Sci U S A. 92, 10678-10682

158 Cho, S. Y. and Klemke, R. L. (2000) Extracellular-regulated kinase activation and CAS/Crk coupling regulate cell migration and suppress apoptosis during invasion of the extracellular matrix. $\mathrm{J}$ Cell Biol. 149, 223-236 
159 Brami-Cherrier, K., Gervasi, N., Arsenieva, D., Walkiewicz, K., Boutterin, M. C., Ortega, A., Leonard, P. G., Seantier, B., Gasmi, L., Bouceba, T., Kadare, G., Girault, J. A. and Arold, S. T. (2014) FAK dimerization controls its kinase-dependent functions at focal adhesions. EMBO J. 33, 356-370

160 Brugnera, E., Haney, L., Grimsley, C., Lu, M., Walk, S. F., Tosello-Trampont, A. C., Macara, I. G., Madhani, H., Fink, G. R. and Ravichandran, K. S. (2002) Unconventional Rac-GEF activity is mediated through the Dock180-ELMO complex. Nat Cell Biol. 4, 574-582

161 Hsia, D. A., Mitra, S. K., Hauck, C. R., Streblow, D. N., Nelson, J. A., Ilic, D., Huang, S., Li, E., Nemerow, G. R., Leng, J., Spencer, K. S., Cheresh, D. A. and Schlaepfer, D. D. (2003) Differential regulation of cell motility and invasion by FAK. J Cell Biol. 160, 753-767

162 Zhang, X., Moore, S. W., Iskratsch, T. and Sheetz, M. P. (2014) N-WASP-directed actin polymerization activates Cas phosphorylation and lamellipodium spreading. J Cell Sci. 127, 13941405

163 Bellis, S. L., Miller, J. T. and Turner, C. E. (1995) Characterization of tyrosine phosphorylation of paxillin in vitro by focal adhesion kinase. J Biol Chem. 270, 17437-17441

164 Schaller, M. D. and Parsons, J. T. (1995) pp125FAK-dependent tyrosine phosphorylation of paxillin creates a high-affinity binding site for Crk. Mol Cell Biol. 15, 2635-2645

165 Pasapera, A. M., Schneider, I. C., Rericha, E., Schlaepfer, D. D. and Waterman, C. M. (2010) Myosin II activity regulates vinculin recruitment to focal adhesions through FAK-mediated paxillin phosphorylation. J Cell Biol. 188, 877-890

166 Theodosiou, M., Widmaier, M., Bottcher, R. T., Rognoni, E., Veelders, M., Bharadwaj, M., Lambacher, A., Austen, K., Muller, D. J., Zent, R. and Fassler, R. (2016) Kindlin-2 cooperates with talin to activate integrins and induces cell spreading by directly binding paxillin. Elife. 5, e10130

167 Turner, C. E. (2000) Paxillin interactions. J Cell Sci. 113 Pt 23, 4139-4140

168 Lopez-Colome, A. M., Lee-Rivera, I., Benavides-Hidalgo, R. and Lopez, E. (2017) Paxillin: a crossroad in pathological cell migration. J Hematol Oncol. 10, 50

169 Cai, X., Li, M., Vrana, J. and Schaller, M. D. (2006) Glycogen synthase kinase 3- and extracellular signal-regulated kinase-dependent phosphorylation of paxillin regulates cytoskeletal rearrangement. Mol Cell Biol. 26, 2857-2868

170 Deakin, N. O. and Turner, C. E. (2008) Paxillin comes of age. J Cell Sci. 121, 2435-2444

171 Hu, Y. L., Lu, S., Szeto, K. W., Sun, J., Wang, Y., Lasheras, J. C. and Chien, S. (2014) FAK and paxillin dynamics at focal adhesions in the protrusions of migrating cells. Sci Rep. 4, 6024

172 Deramaudt, T. B., Dujardin, D., Noulet, F., Martin, S., Vauchelles, R., Takeda, K. and Ronde, P. (2014) Altering FAK-paxillin interactions reduces adhesion, migration and invasion processes. PLoS One. 9, e92059

173 Huveneers, S. and Danen, E. H. (2009) Adhesion signaling - crosstalk between integrins, Src and Rho. J Cell Sci. 122, 1059-1069

174 Derivery, E. and Gautreau, A. (2010) Generation of branched actin networks: assembly and regulation of the N-WASP and WAVE molecular machines. Bioessays. 32, 119-131

175 Derivery, E., Lombard, B., Loew, D. and Gautreau, A. (2009) The Wave complex is intrinsically inactive. Cell Motil Cytoskeleton. 66, 777-790

176 Lebensohn, A. M. and Kirschner, M. W. (2009) Activation of the WAVE complex by coincident signals controls actin assembly. Mol Cell. 36, 512-524

177 Oikawa, T., Yamaguchi, H., Itoh, T., Kato, M., Ijuin, T., Yamazaki, D., Suetsugu, S. and Takenawa, T. (2004) PtdIns(3,4,5)P3 binding is necessary for WAVE2-induced formation of lamellipodia. Nat Cell Biol. 6, 420-426 
178 Reiske, H. R., Kao, S. C., Cary, L. A., Guan, J. L., Lai, J. F. and Chen, H. C. (1999) Requirement of phosphatidylinositol 3-kinase in focal adhesion kinase-promoted cell migration. J Biol Chem. 274, 12361-12366

179 Weiger, M. C., Wang, C. C., Krajcovic, M., Melvin, A. T., Rhoden, J. J. and Haugh, J. M. (2009) Spontaneous phosphoinositide 3-kinase signaling dynamics drive spreading and random migration of fibroblasts. J Cell Sci. 122, 313-323

180 Chen, Z., Borek, D., Padrick, S. B., Gomez, T. S., Metlagel, Z., Ismail, A. M., Umetani, J., Billadeau, D. D., Otwinowski, Z. and Rosen, M. K. (2010) Structure and control of the actin regulatory WAVE complex. Nature. 468, 533-538

181 Mendoza, M. C., Er, E. E., Zhang, W., Ballif, B. A., Elliott, H. L., Danuser, G. and Blenis, J. (2011) ERK-MAPK drives lamellipodia protrusion by activating the WAVE2 regulatory complex. Mol Cell. 41, 661-671

182 Ardern, H., Sandilands, E., Machesky, L. M., Timpson, P., Frame, M. C. and Brunton, V. G. (2006) Src-dependent phosphorylation of Scar1 promotes its association with the Arp2/3 complex. Cell Motil Cytoskeleton. 63, 6-13

183 Miyamoto, Y., Yamauchi, J. and Tanoue, A. (2008) Cdk5 phosphorylation of WAVE2 regulates oligodendrocyte precursor cell migration through nonreceptor tyrosine kinase Fyn. J Neurosci. 28, 8326-8337

184 Carragher, N. O., Westhoff, M. A., Fincham, V. J., Schaller, M. D. and Frame, M. C. (2003) A novel role for FAK as a protease-targeting adaptor protein: regulation by p42 ERK and Src. Curr Biol. 13, $1442-1450$

185 Webb, D. J., Donais, K., Whitmore, L. A., Thomas, S. M., Turner, C. E., Parsons, J. T. and Horwitz, A. F. (2004) FAK-Src signalling through paxillin, ERK and MLCK regulates adhesion disassembly. Nat Cell Biol. 6, 154-161

186 Misra, A., Lim, R. P., Wu, Z. and Thanabalu, T. (2007) N-WASP plays a critical role in fibroblast adhesion and spreading. Biochem Biophys Res Commun. 364, 908-912

187 Shortrede, J. E., Uzair, I. D., Neira, F. J., Flamini, M. I. and Sanchez, A. M. (2016) Paxillin, a novel controller in the signaling of estrogen to FAK/N-WASP/Arp2/3 complex in breast cancer cells. Mol Cell Endocrinol. 430, 56-67

188 Ring, C., Ginsberg, M. H., Haling, J. and Pendergast, A. M. (2011) Abl-interactor-1 (Abi1) has a role in cardiovascular and placental development and is a binding partner of the alpha4 integrin. Proc Natl Acad Sci U S A. 108, 149-154

189 Guan, J. L. and Hynes, R. O. (1990) Lymphoid cells recognize an alternatively spliced segment of fibronectin via the integrin receptor alpha 4 beta 1. Cell. 60, 53-61

190 Gares, S. L. and Pilarski, L. M. (2000) Balancing thymocyte adhesion and motility: a functional linkage between beta1 integrins and the motility receptor RHAMM. Dev Immunol. 7, 209225

191 Neuhaus, H., Hu, M. C., Hemler, M. E., Takada, Y., Holzmann, B. and Weissman, I. L. (1991) Cloning and expression of cDNAs for the alpha subunit of the murine lymphocyte-Peyer's patch adhesion molecule. J Cell Biol. 115, 1149-1158

192 Pinco, K. A., Liu, S. and Yang, J. T. (2001) alpha4 integrin is expressed in a subset of cranial neural crest cells and in epicardial progenitor cells during early mouse development. Mech Dev. 100, 99-103

193 Pinco, K. A., He, W. and Yang, J. T. (2002) alpha4beta1 integrin regulates lamellipodia protrusion via a focal complex/focal adhesion-independent mechanism. Mol Biol Cell. 13, 3203-3217 
194 Goldfinger, L. E., Han, J., Kiosses, W. B., Howe, A. K. and Ginsberg, M. H. (2003) Spatial restriction of alpha4 integrin phosphorylation regulates lamellipodial stability and alpha4beta1dependent cell migration. J Cell Biol. 162, 731-741

195 Charras, G. and Sahai, E. (2014) Physical influences of the extracellular environment on cell migration. Nat Rev Mol Cell Biol. 15, 813-824

196 Giannone, G., Dubin-Thaler, B. J., Rossier, O., Cai, Y., Chaga, O., Jiang, G., Beaver, W., Dobereiner, H. G., Freund, Y., Borisy, G. and Sheetz, M. P. (2007) Lamellipodial actin mechanically links myosin activity with adhesion-site formation. Cell. 128, 561-575

197 Stricker, J., Beckham, Y., Davidson, M. W. and Gardel, M. L. (2013) Myosin II-mediated focal adhesion maturation is tension insensitive. PLoS One. 8, e70652

198 Plotnikov, S. V., Pasapera, A. M., Sabass, B. and Waterman, C. M. (2012) Force fluctuations within focal adhesions mediate ECM-rigidity sensing to guide directed cell migration. Cell. 151, 15131527

199 Humphries, J. D., Wang, P., Streuli, C., Geiger, B., Humphries, M. J. and Ballestrem, C. (2007) Vinculin controls focal adhesion formation by direct interactions with talin and actin. J Cell Biol. 179, 1043-1057

200 Elosegui-Artola, A., Oria, R., Chen, Y., Kosmalska, A., Perez-Gonzalez, C., Castro, N., Zhu, C., Trepat, X. and Roca-Cusachs, P. (2016) Mechanical regulation of a molecular clutch defines force transmission and transduction in response to matrix rigidity. Nat Cell Biol. 18, 540-548

201 Hu, K., Ji, L., Applegate, K. T., Danuser, G. and Waterman-Storer, C. M. (2007) Differential Transmission of Actin Motion Within Focal Adhesions. Science. 315, 111-115

202 Iba, T. and Sumpio, B. E. (1991) Morphological response of human endothelial cells subjected to cyclic strain in vitro. Microvasc Res. 42, 245-254

203 Yoshigi, M., Hoffman, L. M., Jensen, C. C., Yost, H. J. and Beckerle, M. C. (2005) Mechanical force mobilizes zyxin from focal adhesions to actin filaments and regulates cytoskeletal reinforcement. J Cell Biol. 171, 209-215

204 Hirata, H., Tatsumi, H. and Sokabe, M. (2008) Mechanical forces facilitate actin polymerization at focal adhesions in a zyxin-dependent manner. J Cell Sci. 121, 2795-2804

205 Lele, T. P., Pendse, J., Kumar, S., Salanga, M., Karavitis, J. and Ingber, D. E. (2006) Mechanical forces alter zyxin unbinding kinetics within focal adhesions of living cells. J Cell Physiol. 207, 187-194

206 Colombelli, J., Besser, A., Kress, H., Reynaud, E. G., Girard, P., Caussinus, E., Haselmann, U., Small, J. V., Schwarz, U. S. and Stelzer, E. H. (2009) Mechanosensing in actin stress fibers revealed by a close correlation between force and protein localization. J Cell Sci. 122, 1665-1679

207 Chan, M. W., Chaudary, F., Lee, W., Copeland, J. W. and McCulloch, C. A. (2010) Forceinduced myofibroblast differentiation through collagen receptors is dependent on mammalian diaphanous (mDia). J Biol Chem. 285, 9273-9281

208 Bharadwaj, M., Strohmeyer, N., Colo, G. P., Helenius, J., Beerenwinkel, N., Schiller, H. B., Fassler, R. and Muller, D. J. (2017) alphaV-class integrins exert dual roles on alpha5beta1 integrins to strengthen adhesion to fibronectin. Nat Commun. 8, 14348

209 Palamidessi, A., Malinverno, C., Frittoli, E., Corallino, S., Barbieri, E., Sigismund, S., Beznoussenko, G. V., Martini, E., Garre, M., Ferrara, I., Tripodo, C., Ascione, F., Cavalcanti-Adam, E. A., Li, Q., Di Fiore, P. P., Parazzoli, D., Giavazzi, F., Cerbino, R. and Scita, G. (2019) Unjamming overcomes kinetic and proliferation arrest in terminally differentiated cells and promotes collective motility of carcinoma. Nat Mater. 18, 1252-1263

210 Geiger, B. (2006) A role for p130Cas in mechanotransduction. Cell. 127, 879-881 
211 Lu, C., Wu, F., Qiu, W. and Liu, R. (2013) P130Cas substrate domain is intrinsically disordered as characterized by single-molecule force measurements. Biophys Chem. 180-181, 37-43

212 Sawada, Y., Tamada, M., Dubin-Thaler, B. J., Cherniavskaya, O., Sakai, R., Tanaka, S. and Sheetz, M. P. (2006) Force sensing by mechanical extension of the Src family kinase substrate p130Cas. Cell. 127, 1015-1026

213 Branis, J., Pataki, C., Sporrer, M., Gerum, R. C., Mainka, A., Cermak, V., Goldmann, W. H., Fabry, B., Brabek, J. and Rosel, D. (2017) The role of focal adhesion anchoring domains of CAS in mechanotransduction. Sci Rep. 7, 46233

214 Janostiak, R., Pataki, A. C., Brabek, J. and Rosel, D. (2014) Mechanosensors in integrin signaling: the emerging role of p130Cas. Eur J Cell Biol. 93, 445-454

215 Law, S. F., Zhang, Y. Z., Fashena, S. J., Toby, G., Estojak, J. and Golemis, E. A. (1999) Dimerization of the docking/adaptor protein HEF1 via a carboxy-terminal helix-loop-helix domain. Exp Cell Res. 252, 224-235

216 Janostiak, R., Brabek, J., Auernheimer, V., Tatarova, Z., Lautscham, L. A., Dey, T., Gemperle, J., Merkel, R., Goldmann, W. H., Fabry, B. and Rosel, D. (2014) CAS directly interacts with vinculin to control mechanosensing and focal adhesion dynamics. Cell Mol Life Sci. 71, 727-744

217 Janostiak, R., Tolde, O., Bruhova, Z., Novotny, M., Hanks, S. K., Rosel, D. and Brabek, J. (2011) Tyrosine phosphorylation within the SH3 domain regulates CAS subcellular localization, cell migration, and invasiveness. Mol Biol Cell. 22, 4256-4267

218 Honda, H., Nakamoto, T., Sakai, R. and Hirai, H. (1999) p130(Cas), an assembling molecule of actin filaments, promotes cell movement, cell migration, and cell spreading in fibroblasts. Biochem Biophys Res Commun. 262, 25-30

219 Klemke, R. L., Leng, J., Molander, R., Brooks, P. C., Vuori, K. and Cheresh, D. A. (1998) CAS/Crk coupling serves as a "molecular switch" for induction of cell migration. J Cell Biol. 140, 961-972

220 Kostic, A. and Sheetz, M. P. (2006) Fibronectin rigidity response through Fyn and p130Cas recruitment to the leading edge. Mol Biol Cell. 17, 2684-2695

221 Tamada, M., Sheetz, M. P. and Sawada, Y. (2004) Activation of a signaling cascade by cytoskeleton stretch. Dev Cell. 7, 709-718

222 Mun, H. and Jeon, T. J. (2012) Regulation of actin cytoskeleton by Rap1 binding to RacGEF1. Mol Cells. 34, 71-76

223 Du, J., Chen, X., Liang, X., Zhang, G., Xu, J., He, L., Zhan, Q., Feng, X. Q., Chien, S. and Yang, C. (2011) Integrin activation and internalization on soft ECM as a mechanism of induction of stem cell differentiation by ECM elasticity. Proc Natl Acad Sci U S A. 108, 9466-9471

224 Raab, M., Swift, J., Dingal, P. C., Shah, P., Shin, J. W. and Discher, D. E. (2012) Crawling from soft to stiff matrix polarizes the cytoskeleton and phosphoregulates myosin-II heavy chain. J Cell Biol. 199, 669-683

225 Chodniewicz, D. and Klemke, R. L. (2004) Regulation of integrin-mediated cellular responses through assembly of a CAS/Crk scaffold. Biochim Biophys Acta. 1692, 63-76

226 Jacquemet, G., Stubb, A., Saup, R., Miihkinen, M., Kremneva, E., Hamidi, H. and Ivaska, J. (2019) Filopodome Mapping Identifies p130Cas as a Mechanosensitive Regulator of Filopodia Stability. Curr Biol. 29, 202-216 e207

227 Mui, K. L., Chen, C. S. and Assoian, R. K. (2016) The mechanical regulation of integrincadherin crosstalk organizes cells, signaling and forces. J Cell Sci. 129, 1093-1100

228 Changede, R. and Sheetz, M. (2017) Integrin and cadherin clusters: A robust way to organize adhesions for cell mechanics. Bioessays. 39, 1-12 
229 Thiam, H. R., Vargas, P., Carpi, N., Crespo, C. L., Raab, M., Terriac, E., King, M. C., Jacobelli, J., Alberts, A. S., Stradal, T., Lennon-Dumenil, A. M. and Piel, M. (2016) Perinuclear Arp2/3-driven actin polymerization enables nuclear deformation to facilitate cell migration through complex environments. Nat Commun. 7, 10997

230 Letort, G., Ennomani, H., Gressin, L., Thery, M. and Blanchoin, L. (2015) Dynamic reorganization of the actin cytoskeleton. F1000Res. 4

231 Schonichen, A. and Geyer, M. (2010) Fifteen formins for an actin filament: a molecular view on the regulation of human formins. Biochim Biophys Acta. 1803, 152-163

232 Bradbury, P. M., Turner, K., Mitchell, C., Griffin, K. R., Middlemiss, S., Lau, L., Dagg, R., Taran, E., Cooper-White, J., Fabry, B. and O'Neill, G. M. (2017) The focal adhesion targeting domain of p130Cas confers a mechanosensing function. J Cell Sci. 130, 1263-1273 

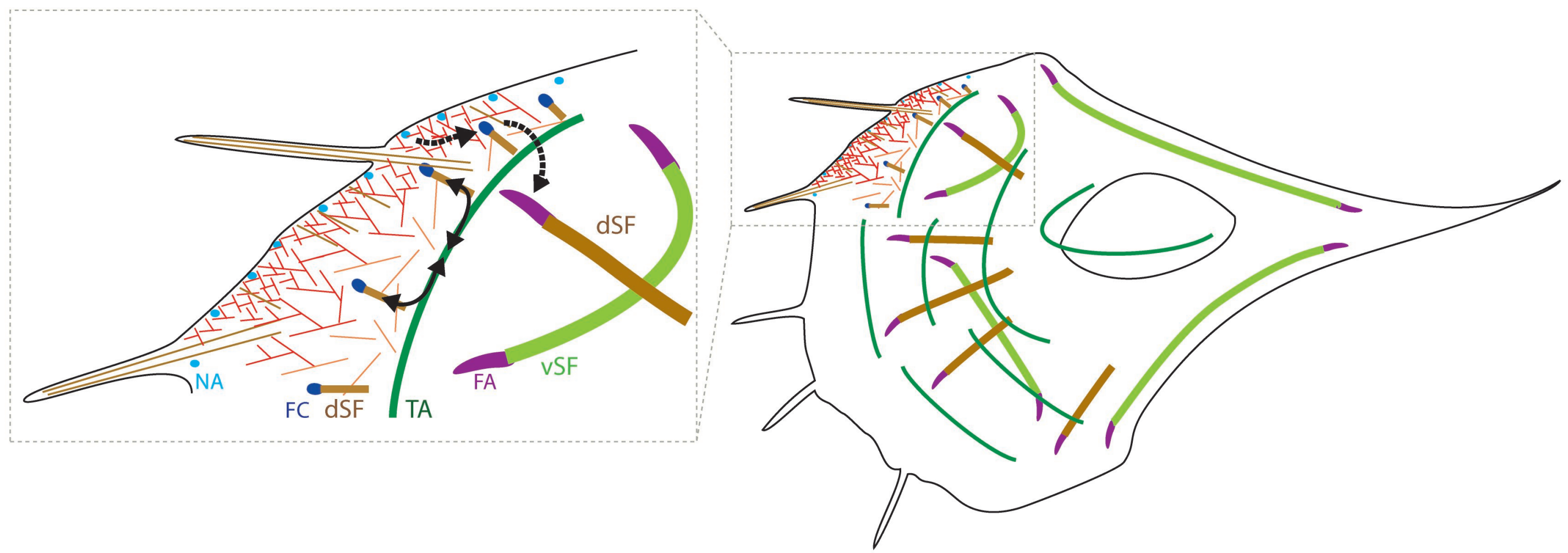

Focal Adhesion (FA)

- Focal Complex (FC)

- $\quad$ Nascent Adhesion (NA)

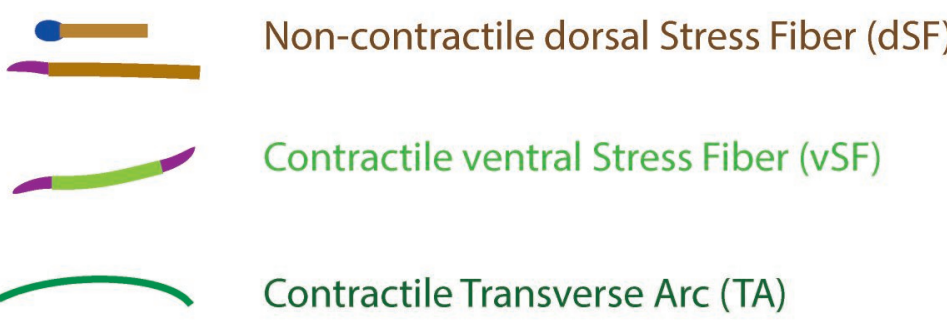

Actin bundles

泣 Branched actin network

F- Debranching actin network

Figure 1 

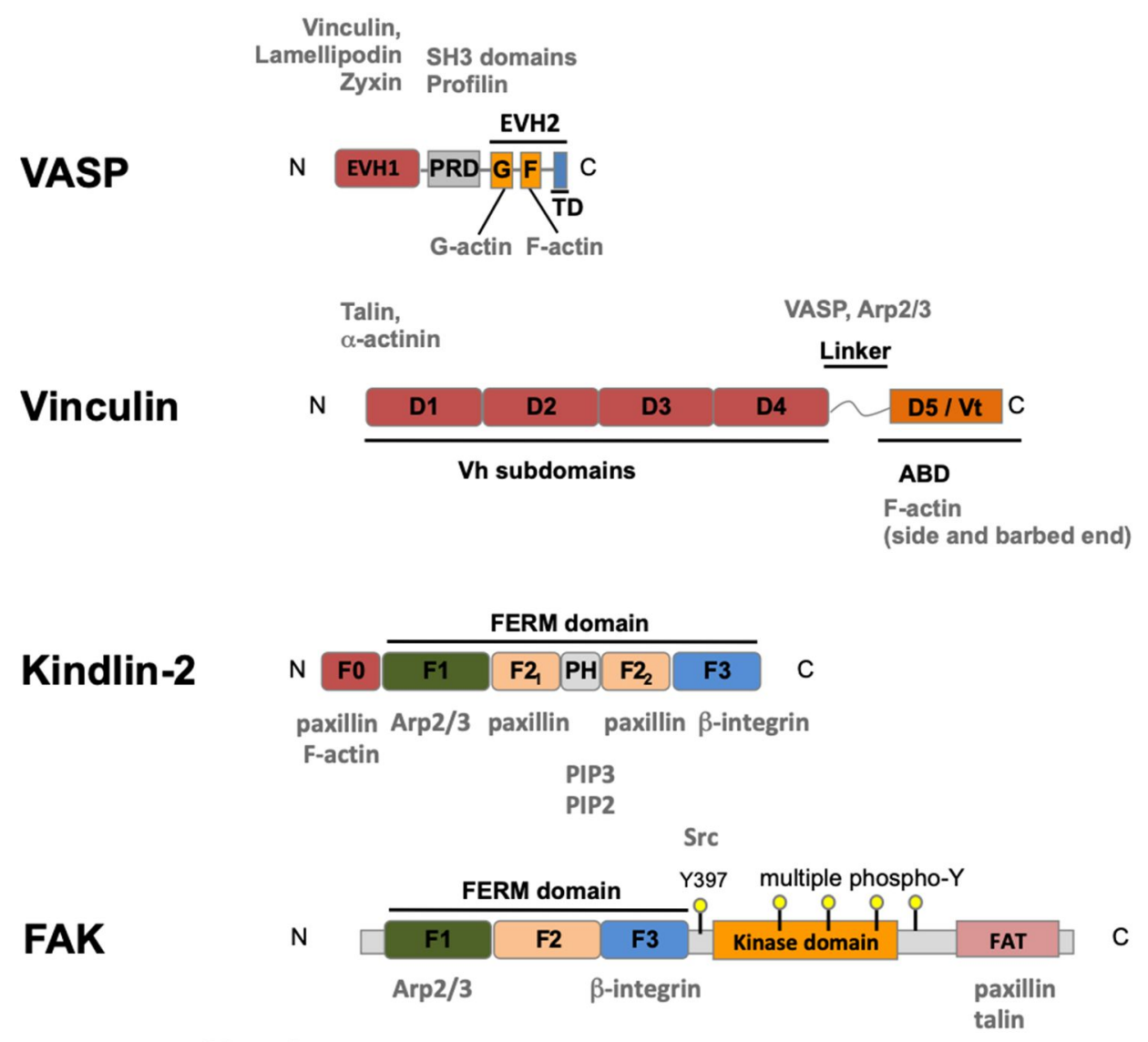

Talin

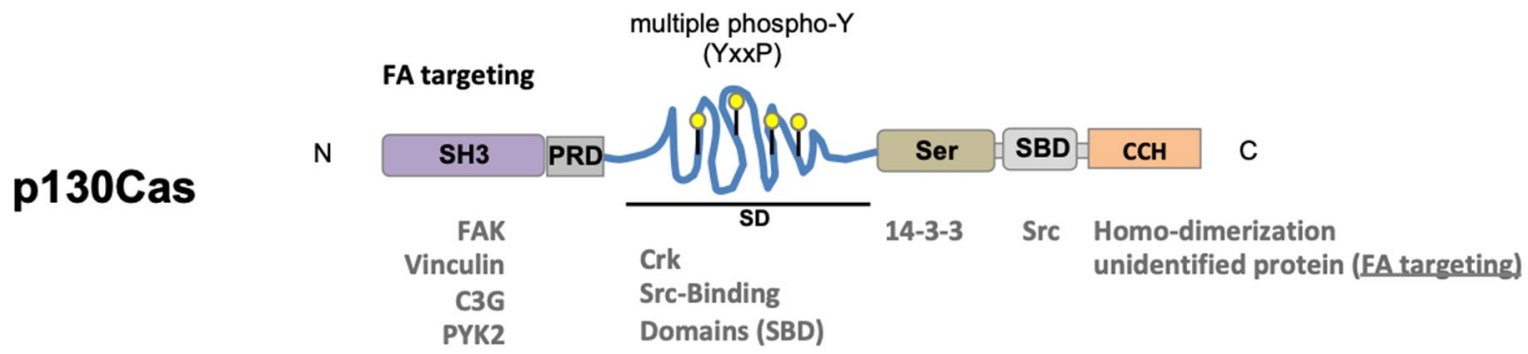




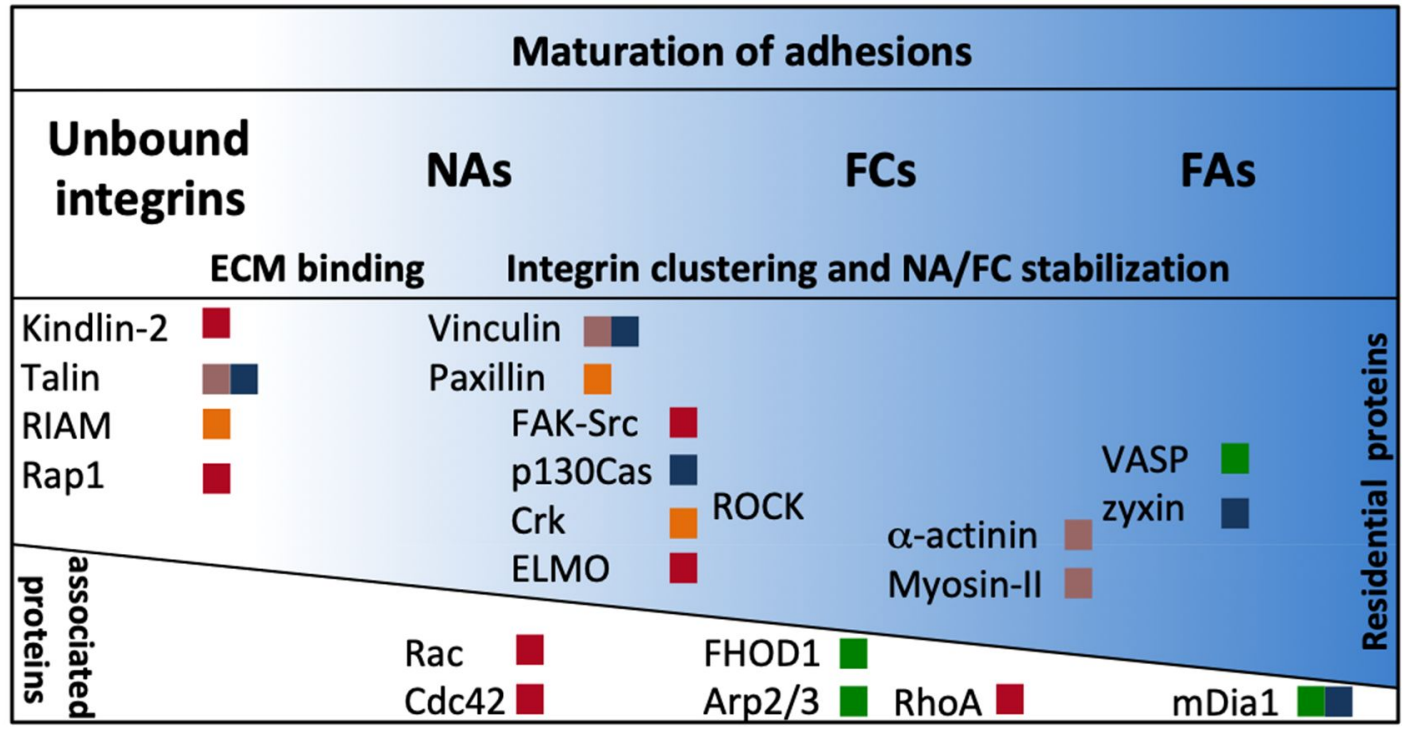

Actin binding proteins Actin regulators

Scaffolding proteins

- Signaling proteins

Mechanotransduction

Figure 3 
A

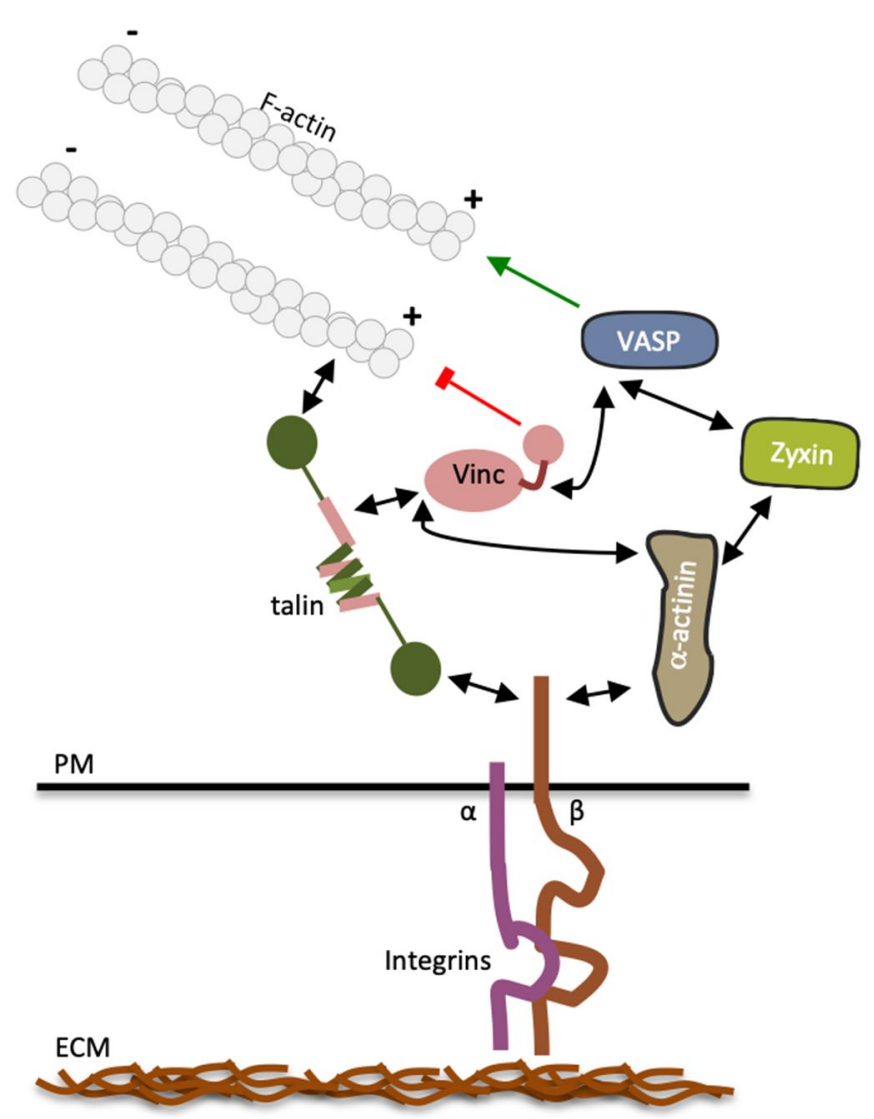

B

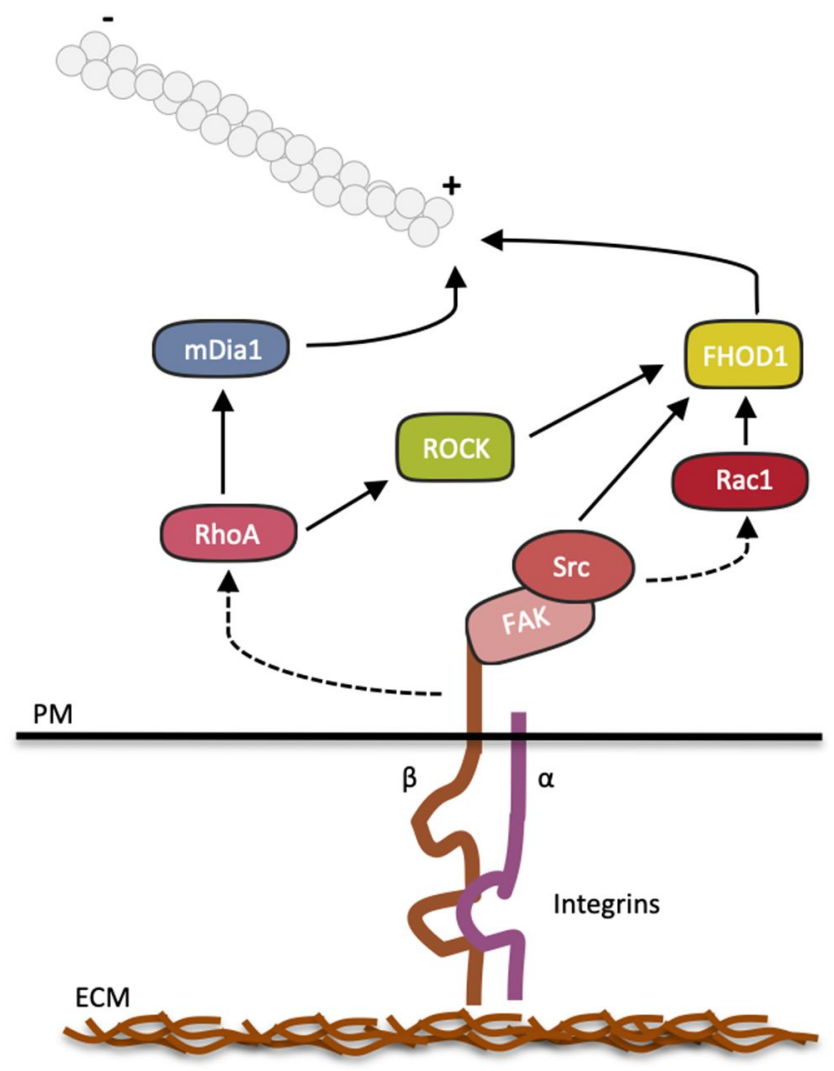

Figure 4 


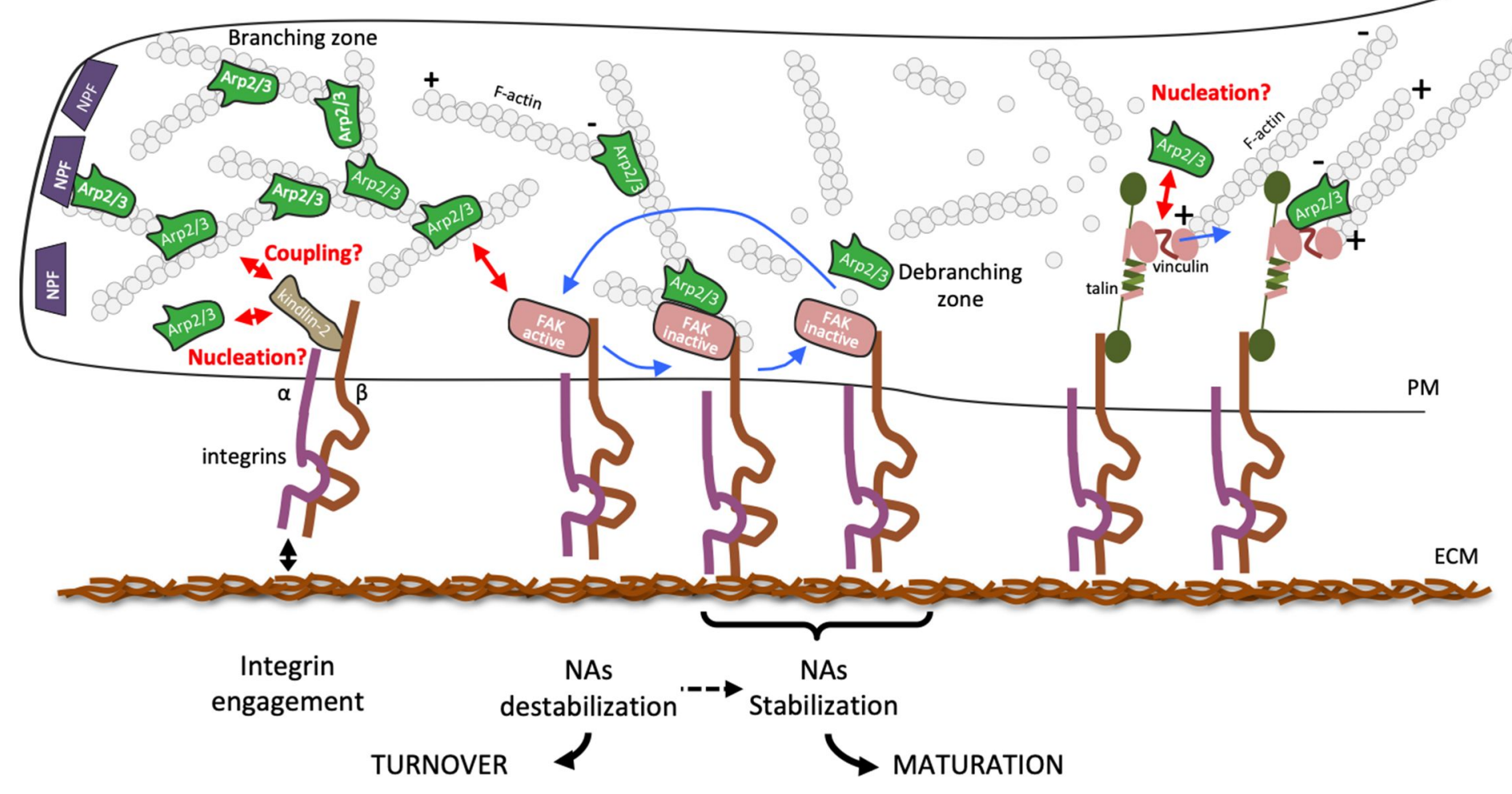

Figure 5 
